\title{
Interactions between Typhoon Choi-wan (2009) and the Kuroshio Extension System
}

\author{
Akiyoshi Wada, Norihisa Usui, and Masaru Kunii \\ Meteorological Research Institute, 1-1 Nagamine, Tsukuba, Ibaraki 305-0052, Japan \\ Correspondence should be addressed to Akiyoshi Wada; awada@mri-jma.go.jp
}

Received 26 February 2013; Revised 9 May 2013; Accepted 31 May 2013

Academic Editor: Bin Liu

Copyright ( 2013 Akiyoshi Wada et al. This is an open access article distributed under the Creative Commons Attribution License, which permits unrestricted use, distribution, and reproduction in any medium, provided the original work is properly cited.

\begin{abstract}
We investigated interactions between Typhoon Choi-wan (2009) and the Kuroshio Extension system with a coupled atmospherewave-ocean model in 14 numerical simulations performed with initial conditions obtained from daily oceanic reanalysis data for the northwestern Pacific Ocean from September 12 to September 25, 2009. Preexisting oceanic conditions affected the simulated central pressure and the inner-core axisymmetric structure of the simulated typhoon differently during the intensification, mature, and decaying phases, but they had little impact on the simulated track. Among the simulations, the simulated central pressure range during the mature phase was $\sim 10 \mathrm{hPa}$. Simulated central pressure was highly correlated with the axisymmetric mean horizontal specific humidity flux between radii of 50 and $150 \mathrm{~km}$ and altitudes of 20 to $2000 \mathrm{~m}$, suggesting that this flux has potential as a new metric for predicting tropical cyclone intensity. Variations in preexisting oceanic conditions in the Kuroshio Extension region on the simulated atmospheric and oceanic horizontal fields affected the typhoon and a nearby stationary front differently. Around the stationary front, the impact on hourly precipitation was closely related to that on surface wind speed, whereas the impact on surface temperature was greatly affected by that on sea surface temperature through the latent heat flux.
\end{abstract}

\section{Introduction}

Tropical cyclones (TCs) are generated over tropical and subtropical oceans when sea surface temperature (SST) is above $26.5^{\circ} \mathrm{C}$ [1]. Oceanic conditions play a crucial role in TC intensification and the maximum intensity reached [24]. The sea surface becomes cooler beneath and behind a TC, primarily as a result of the vertical turbulent mixing and upwelling caused by the passage of the TC [5-7]. This TC-induced sea surface cooling negatively affects TC intensification and the maximum intensity reached [8]. In 1989, for example, typhoons Nancy and Owen produced remarkable sea surface cooling $\left(\sim 9^{\circ} \mathrm{C}\right)$ north of the Kuroshio Extension [9] in the northern eddy zone [10]. Thus, for precise prediction of TC intensification, maximum TC intensity, and the oceanic response to the TC, it is indispensable to consider interactions between the TC and the ocean.

The Kuroshio Extension is the region of the North Pacific Ocean $\left(30^{\circ}-40^{\circ} \mathrm{N}, 141^{\circ}-175^{\circ} \mathrm{E}\right.$ [11] $)$ occupied by the Kuroshio Current after it separates from the coast of Japan at around $35^{\circ} \mathrm{N}, 140^{\circ} \mathrm{E}$ [12]. The SST gradient maximum that parallels the Kuroshio Extension axis defines the Kuroshio Extension front [13]. In this region, SST and sea surface height anomalies sometimes propagate westward, typically on a time scale of a few months, in association with the propagation of the surface wind speed anomaly [14].

Typhoon Choi-wan (2009), which passed through this region in September 2009, offers an opportunity to examine interactions between a TC and the Kuroshio Extension system. Satellite altimeter (http://www.aviso.oceanobs.com/) observations obtained between September 2 and September 30, 2009 reveal how sea surface height changed during the passage of Choi-wan (Figure 1). On, September 2, 2009, high sea surface height anomalies were observed in a region of anticyclonic circulation north of the Kuroshio Extension Observatory (KEO) moored buoy (Figure 1). By September 16 , an area of low sea surface height anomalies extended to near the KEO buoy as a result of the deepening of a trough over the axis of the Kuroshio Extension around $34^{\circ} \mathrm{N}$ and $145^{\circ} \mathrm{E}$. By September 30, after the passage of Choi-wan at the KEO buoy on September 19, a cold eddy had separated from the trough and approached the buoy from the 

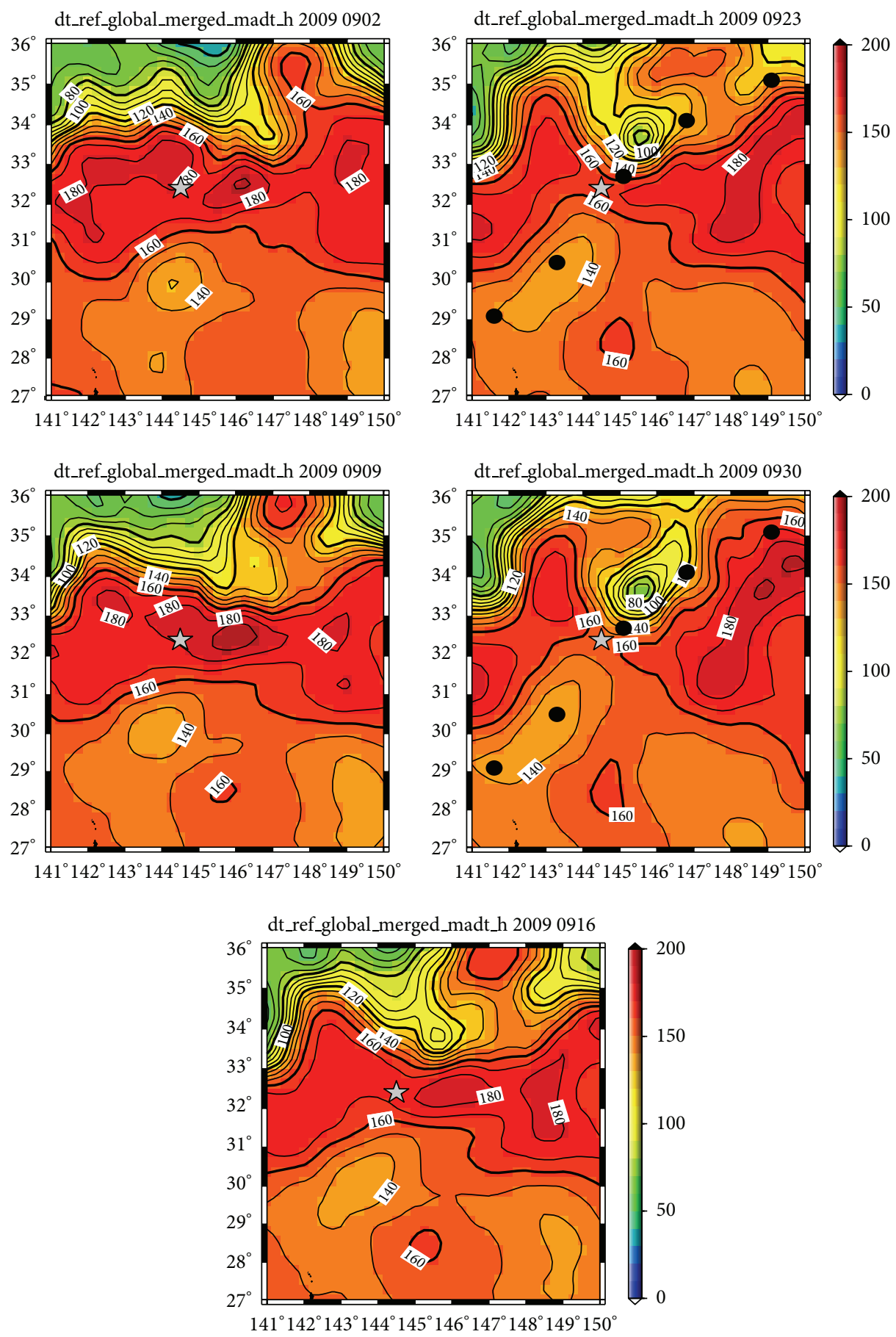

FIGURE 1: Horizontal distributions of sea surface height anomalies observed by satellite altimeter (http://www.aviso.oceanobs.com/) at 7-day intervals between September 2 and September 30, 2009, which includes the period of the passage of Typhoon Choi-wan. The maps were created by using the delayed time reference series product of weekly mean sea level height. The contour interval is $10 \mathrm{~cm}$. In each panel, the location of the KEO moored buoy is shown by the star. The track of Typhoon Choi-wan (from the Regional Specialized Regional Center (RSMC) - Tokyo best-track data set) is shown by black circles in two panels.

northeast. In addition, a cyclonic eddy centered on $30^{\circ} \mathrm{N}$, $143^{\circ} \mathrm{E}$ elongated and intensified after the passage of the typhoon. This intensification of this cyclonic eddy implies the existence of a cold wake behind the typhoon [7]. Thus, the passage of Choi-wan through the Kuroshio Extension region resulted in complex oceanic responses, and by studying those responses and their impacts on the typhoon itself and on atmospheric conditions generally we can gain interesting insights into air-sea interactions.

The lifecycle of a TC, and its transition to an extratropical cyclone in particular, is assumed to be sensitive to the underlying SST distribution. Numerical experiments 
simulating the sensitivity of a TC to SST have shown that both the track and intensity of a TC are influenced by the horizontal distribution of SST [15] and its perturbations [16, 17]. For more precise TC predictions by numerical models, therefore, accurate knowledge of the initial SST conditions is essential. However, not only SST but also water temperature and salinity in the ocean interior are changed rapidly and dramatically by the passage of a TC [7] and by other atmospheric disturbances due to the upper oceanic response. Thus, to understand the oceanic response to a TC, not only SST but also water temperature and salinity in the ocean interior are important.

In general, numerical simulations performed with a coupled atmosphere-ocean model can be used to evaluate the uncertainty of the effect of variations in temperature and salinity in the ocean interior in the Kuroshio Extension region on a TC. In fact, stratification of the upper ocean, which is determined by temperature and salinity in the ocean interior, is affected by passage of a typhoon [7]. In addition, by analyzing the results of numerical simulations, we can improve our understanding of the effect of the preexisting upperocean environment on a TC as well as that of the underlying SST. For example, sea surface cooling induced by Typhoon Hai-Tang (2005) in the subtropical western North Pacific Ocean was responsible for formation of the eyewall of the simulated TC, whereas changes in the surrounding SST conditions on a climate time scale affected the spiral rainband that accompanied the simulated TC [18]. Because the Kuroshio Extension system, which is in the mid-latitude ocean, typically varies nonlinearly at a time scale of a few months [3], changes in the preexisting SST distribution as well as those due to sea surface cooling induced by a TC might affect the lifecycle of a TC and its transition to an extratropical cyclone. However, the effect of variation in the Kuroshio Extension system on a weather-forecasting time scale on the results of a TC simulation performed with a coupled atmosphere-wave-ocean model has not yet been investigated.

The purpose of this study was to clarify the effects of weekly time scale variation in preexisting oceanic conditions in the region of the Kuroshio Extension on TC-ocean interactions during each TC phase. We used a coupled atmospherewave-ocean model [19] to perform 14 numerical simulations of Typhoon Choi-wan with 14 different sets of oceanic initial conditions. The sets of initial conditions were obtained from daily oceanic reanalysis data for 12 September to September 25, 2009, calculated by the North Western Pacific version of the Meteorological Research Institute (MRI) ocean variational estimation (MOVE) system with a horizontal grid spacing of $0.1^{\circ}$ [20]. Among the 14 sets of initial conditions obtained from daily MOVE data, variation was high along the track of Choi-wan and adjacent to the Kuroshio Extension axis (Figure 2). Thus, the Kuroshio Extension system region showed large SST variation, and the passage of the typhoon also caused large variation in SST.

This rest of this paper is structured as follows. In Section 2 , we describe the model and the experimental design. In Section 3, we present the results of the numerical simulations and of their validation by KEO observations. In Section 4, we discuss the impacts of preexisting oceanic conditions on the

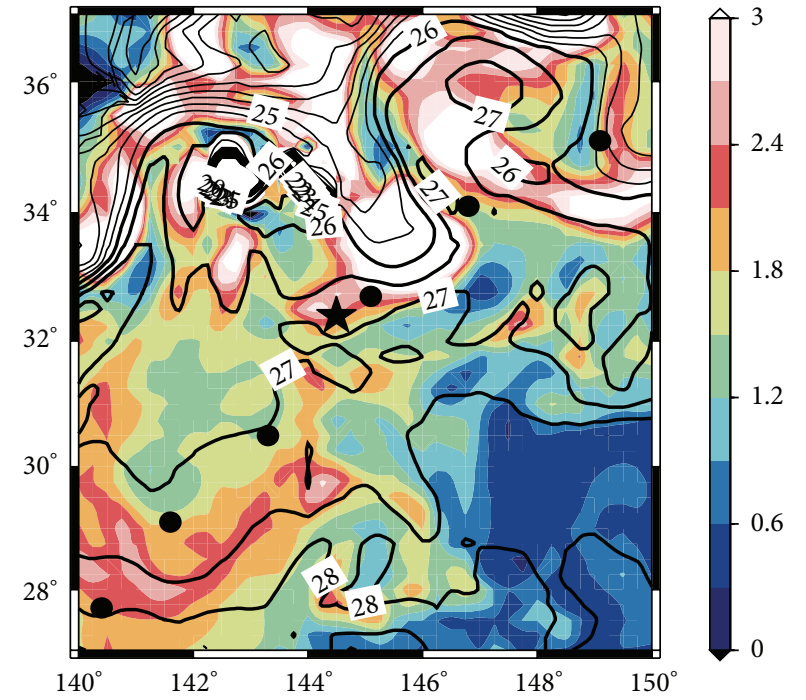

FIGURE 2: Horizontal distribution of mean sea surface temperature (contours) (average of the 14 initial values in the daily MOVE data) and its standard deviation (color scale) at the initial integration time. The contour interval is $0.5^{\circ} \mathrm{C}$, the star shows the location of the KEO moored buoy, and the black circles show the track of Typhoon Choiwan.

TC for each TC phase and ways to improve typhoon simulations. Section 5 is the conclusion.

\section{Model and Experiment Design}

2.1. Coupled Model. We used a regional coupled atmospherewave-ocean model [19] consisting of a nonhydrostatic atmosphere mesoscale model (NHM), a third-generation ocean wave model (MRI-III) developed by the MRI and the Japan Meteorological Agency (JMA), and a multilayer ocean model developed by MRI, based on the formulation of Bender et al. [21]. The coupled atmosphere-wave-ocean model that included an oceanic sublayer scheme $[22,23]$ was used previously to investigate the impact of variations in preexisting oceanic conditions on predictions of Typhoon Hai-Tang (2005), and the numerical study results showed that during the intensification phase, a relatively rapid intensification of Hai-Tang occurred where the typhoon passed over a relatively deep mixed layer [19].

For comparison and to show how the use of a coupled model affected the simulation results, we also performed some simulations with the uncoupled NHM with the same initial conditions.

In this study, we used the same NHM and multilayer ocean model as were used by Wada and Usui [18] and Wada et al. [19]. The NHM incorporates the following physical schemes: an explicit three-ice bulk microphysics [24]; a resistance law for sensible and latent heat fluxes and wind stress in the surface boundary layer; exchange coefficients for sensible and latent heat fluxes and wind stress over the sea, determined by using Kondo's bulk formulas [25]; a turbulent closure model in the atmospheric boundary layer [26, 27]; 
and an atmospheric radiation scheme [28]. No convective parameterization was used in the present study.

The reduced-gravity multilayer ocean model [6] consists of three layers bounded by four levels. The upper mixed layer has a vertically uniform density, which was determined from daily MOVE data by assuming a difference in density from the surface of no more than $0.25 \mathrm{~g} \mathrm{~m}^{-3}$, and a thickness of up to $200 \mathrm{~m}$. The middle layer is the seasonal thermocline, where the vertical temperature gradient is largest among the three layers; its base is at no more than $600 \mathrm{~m}$ depth. The bottom layer is assumed to be undisturbed by entrainment $[18,19]$. The model assumes a maximum water depth of $2000 \mathrm{~m}$. The four levels consist of the surface, the base of the mixed layer/top of the thermocline, the base of the thermocline/top of the bottom layer, and the sea floor. Temperature and salinity are calculated only at the surface and at the base of the mixed layer, whereas layer thickness and ocean current flows are calculated for all layers.

The formulation of MRI-III has been described by Ueno and Kohno [29]. To summarize, the MRI-III predicts wave spectra as a function of space and time by using an energy balance equation that describes the spectral energy input by the wind, the nonlinear transfer of spectral energy due to wave-wave interactions, and the energy dissipation due to breaking surface waves and whitecap formation. Each wave spectrum of the MRI-III has 900 components at a grid, each associated with one of 25 frequencies and one of 36 directions. The wave spectrum frequency is divided into logarithmic units from 0.0375 to $0.3000 \mathrm{~Hz}$. In the present simulations, the ocean wave is assumed to be initially motionless.

The atmosphere-ocean coupling procedure is as follows. Short-wavelength and long-wavelength radiation, sensible and latent heat fluxes, wind stress, and precipitation are provided at every time step to the multilayer ocean model. Land and sea distributions, extracted from GTOPO30 digital elevation data from the U.S. Geological Survey, are provided by the atmosphere model to the multilayer ocean model only at the initial time to ensure that the same land and sea distributions are used by the atmosphere and multilayer ocean models. Ocean bottom topography was obtained from the ETOPO5 data set from the National Oceanic and Atmospheric Administration National Geophysical Data Center; these elevations are spaced at 5-minute intervals of latitude and longitude. SST calculated by the multilayer ocean model was provided for every time step of the ocean model.

A simple ocean wave-ocean coupling procedure is used as follows. Ocean currents in the mixed layer are provided to the MRI-III. The group velocity of ocean waves calculated by the MRI-III is modified by the ocean surface currents. Conversely, wave-induced stresses calculated by the MRI-III are provided to the multilayer ocean model to modify the surface wind stress. The wave-induced stress is also used for estimating the parameter for breaking surface waves, which are induced by wind stress [19].

For the atmosphere-ocean wave coupling procedure, we adopted the formulation of Taylor and Yelland [30], in which surface roughness lengths over the ocean depend on wave steepness. Wind speeds calculated by the NHM are provided to the MRI-III. For simulations performed with

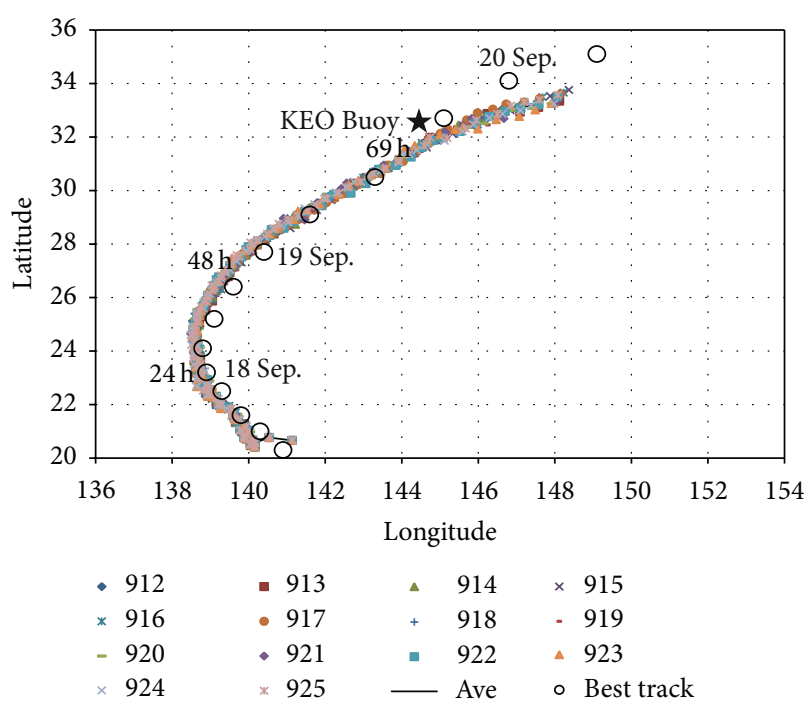

FIgure 3: Best-track positions of Typhoon Choi-wan shown every $6 \mathrm{~h}$, the hourly positions of central pressure obtained by each simulation, and the mean hourly position of central pressures averaged over all simulations. A star mark indicates the location of the KRO buoy.

the uncoupled NHM (i.e., no ocean wave information is available), the surface roughness length is calculated by using the formulation of Kondo [25].

2.2. Experimental Design. The regional coupled model domain consisted of a $661 \times 661$ horizontal grid. The horizontal grid spacing was $6 \mathrm{~km}$, centered at $26^{\circ} \mathrm{N}, 145^{\circ} \mathrm{E}$. The NHM had 40 vertical levels, and the interval between levels varied from $40 \mathrm{~m}$ near the surface to $1180 \mathrm{~m}$ for the uppermost layer. The top height was $\sim 23 \mathrm{~km}$. The time step of the NHM was $20 \mathrm{~s}$, that of the multilayer ocean model was $120 \mathrm{~s}$, and that of the MRI-III was $10 \mathrm{~min}$. The integration time was $96 \mathrm{~h}$, starting at 0000 UTC September 17, 2009, and numerical results from the initial time to $84 \mathrm{~h}$ were used in the analysis.

The set of atmospheric initial and boundary conditions was derived from six-hourly global objective analysis data from JMA with a horizontal grid spacing of $20 \mathrm{~km}$. To improve the simulation of the typhoon's track, the width of lateral boundary relaxation sponge layers was set to 180 grids, corresponding to $1080 \mathrm{~km}$. Initial oceanic conditions, namely, temperature, salinity, layer thickness, and oceanic current velocity, were obtained from daily MOVE data. To prepare the 14 different sets of oceanic initial conditions, we used the daily MOVE data from September 12 to September 25, 2009. Thus, we performed 14 simulations, designated 0912, $0913, \ldots$, and 0925 , with the 14 sets of oceanic initial conditions.

2.3. Typhoon Choi-wan (2009). The lifecycle of Typhoon Choi-wan described here is based on the annual report of Activities of the Regional Specialized Meteorological Center (RSMC) Tokyo-Typhoon Center (http://www.jma.go .jp/jma/jma-eng/jma-center/rsmc-hp-pub-eg/AnnualReport/ 2009/Text/Text2009.pdf). We use the best-track data archived 
by the RSMC Tokyo-Typhoon Center. A tropical depression developed east of Saipan Island $\left(14.3^{\circ} \mathrm{N}, 153.5^{\circ} \mathrm{E}\right)$ at 0000 UTC on September 12, 2009. It moved west-northwest and developed to tropical storm intensity around $15.4^{\circ} \mathrm{N}, 150.9^{\circ} \mathrm{E}$ at 1800 UTC on September 12. The storm turned westward on September 13, and then rapidly developed, reaching typhoon intensity around $15.6^{\circ} \mathrm{N}, 148.3^{\circ} \mathrm{E}$ at $0000 \mathrm{UTC}$ on September 14 and receiving the name Typhoon Choi-wan. Subsequently, the typhoon moved west-northwest again and reached its peak intensity with a maximum sustained 10 min mean wind speed of $\sim 54 \mathrm{~m} \mathrm{~s}^{-1}$ and a central pressure of $915 \mathrm{hPa}$ north of Saipan Island $\left(17.9^{\circ} \mathrm{N}, 145.0^{\circ} \mathrm{E}\right)$ at $1200 \mathrm{UTC}$ on September 15. After recurving west of Iwoto Island around $24.1^{\circ} \mathrm{N}, 138.8^{\circ} \mathrm{E}$ on September 18, Choi-wan moved northeastward, passing north of the Ogasawara Islands. The typhoon became an extratropical cyclone east of Japan around $36.8^{\circ} \mathrm{N}, 152.3^{\circ} \mathrm{E}$ at 1200 UTC on September 20, after its passage over the KEO buoy (Figure 3).

\section{Results}

3.1. Track and Central Pressure Prediction. We first investigated the impact of variations in preexisting oceanic conditions, particularly in the Kuroshio Extension region, on the simulations of Choi-wan's track and central pressure. The mean of the simulated tracks agreed well with the observed best track. Moreover, the spread among the track simulations was narrow, indicating that the impact of the variations in preexisting oceanic conditions on the simulated track was small (Figure 3 ). This result is consistent with that of a previous study of Typhoon Hai-Tang (2005) [18]. It should be noted that the large width used for the lateral boundary sponge layers (Section 2.2) likely suppressed the spread among the track simulations.

Among the 14 simulations, variations in preexisting oceanic conditions first showed an impact on the simulated central pressure results after $12 \mathrm{~h}$ of integration time (Figure $4(\mathrm{a})$ ), and standard deviations of the simulated central pressure were large during the intensification phase (integration time up to $24 \mathrm{~h}$ ). The maximum simulated central pressure range (maximum minus minimum simulated central pressure) of $\sim 10 \mathrm{hPa}$ was reached during the mature phase (integration time between 24 and $48 \mathrm{~h}$ ). This range is smaller than that found in the case of Typhoon Hai-Tang $(\sim 18 \mathrm{hPa})$ [18]. Moreover, different from the previous result [18], the range became small during the decaying phase of Choi-wan (integration time between 48 and $69 \mathrm{~h}$ and later), reflecting the influence of the wide lateral boundary sponge layers.

Among the 14 simulations, the maximum range of the simulated maximum wind speed of $\sim 7 \mathrm{~m} \mathrm{~s}^{-1}$ was also reached during the mature phase (Figure 4(b)). Different from the central pressure results (Figure 4(a)), the maximum wind speed simulated by the coupled model was maintained at a constant value until 0000 UTC on September 20 (Figure 4(b)). The simulated wind-pressure relationship (Figure 4(c)) shows that the leveling off of the simulated maximum wind speed at around $40 \mathrm{~m} \mathrm{~s}^{-1}$ is consistent with the best-track wind-pressure relationship, whereas the empirical relationship described by Koba et al. [31] does not agree well with either the simulated or best-track relationships, particularly during the intensification phase. During the decaying phase (central pressures higher than $960 \mathrm{hPa}$ ), however, the windpressure relationship simulated by the coupled model agrees well with the empirical relationship of Koba et al. [31] and with the best-track data (Figure 4(c)).

Compared with the coupled model results, simulated central pressures obtained with the uncoupled NHM tended to be low (Figure $4(\mathrm{~d})$ ) and simulated maximum wind speeds tended to be high (Figure 4(e)). The difference in the maximum wind speed at the initial time between the coupled model (Figure 4(b)) and the uncoupled NHM (Figure 4(e)) is due to the difference in the formulation of surface roughness length between Kondo [25] and Taylor and Yelland [30]. With the coupled model, the surface roughness lengths based on the formulation of Taylor and Yelland [30] used with the coupled model were high relative to those based on the formulation of Kondo [25]; as a result, surface friction was strong and maximum wind speeds were low. The windpressure relationship obtained with the uncoupled NHM agrees well with the best-track relationship (Figure 4(f)), even though the evolution of central pressure and maximum wind speed differed greatly between the simulated and besttrack results (Figures 4(d) and 4(e)).

3.2. Axisymmetric Structure. The simulated wind-pressure relationship differed depending on the phase of the simulated typhoon (Figure 4(c)). These differences may be attributable to differences in the structure of the simulated typhoon during each phase. For this reason, we investigated the impact of variations in preexisting oceanic conditions on the axisymmetric structure of the simulated Choi-wan at $24 \mathrm{~h}$ (included in the intensification phase), $48 \mathrm{~h}$ (included in the mature phase), and $69 \mathrm{~h}$ (included in the decaying phase).

At $24 \mathrm{~h}$ (Figure 5(a)), the horizontal gradient of the axisymmetric mean equivalent potential temperature of the 14 simulations steepens and the axisymmetric mean latent heat flux is relatively high between $\sim 50$ and $100 \mathrm{~km}$ from the center of the simulated typhoon. By contrast, the axisymmetric mean SST is radially uniform at $\sim 28^{\circ} \mathrm{C}$. In addition, at $24 \mathrm{~h}$, standard deviations of equivalent potential temperature are high above $1500 \mathrm{~m}$ height at radii of $50-100 \mathrm{~km}$. At $48 \mathrm{~h}$, however, the area of standard deviations shifts outward, to about $100-150 \mathrm{~km}$ from the TC center (Figure 5(b)). Moreover, at $48 \mathrm{~h}$, both the axisymmetric mean latent heat flux and the standard deviations of SST are lower inside the mean latent heat flux peak compared with those at $24 \mathrm{~h}$, indicating formation of the ring-shaped eye of the simulated typhoon at the radius of $70 \mathrm{~km}$. With the approach of the simulated typhoon to the Kuroshio Extension region at $69 \mathrm{~h}$, the standard deviations of equivalent potential temperature are relatively high below $1000 \mathrm{~m}$ height around $150-200 \mathrm{~km}$ from the center of the typhoon. At these radii, the axisymmetric mean latent heat flux is relatively high and the mean SST is relatively low compared with those during earlier phases (Figure 5(c)). Thus, the impact of variations in preexisting oceanic conditions on the axisymmetric structure of the simulated typhoon differs according to the simulated phase of Choiwan. 


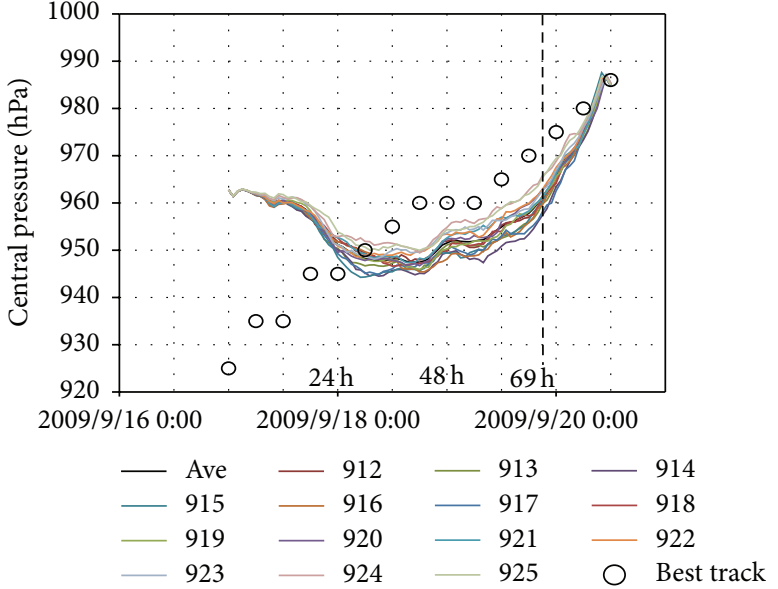

(a)

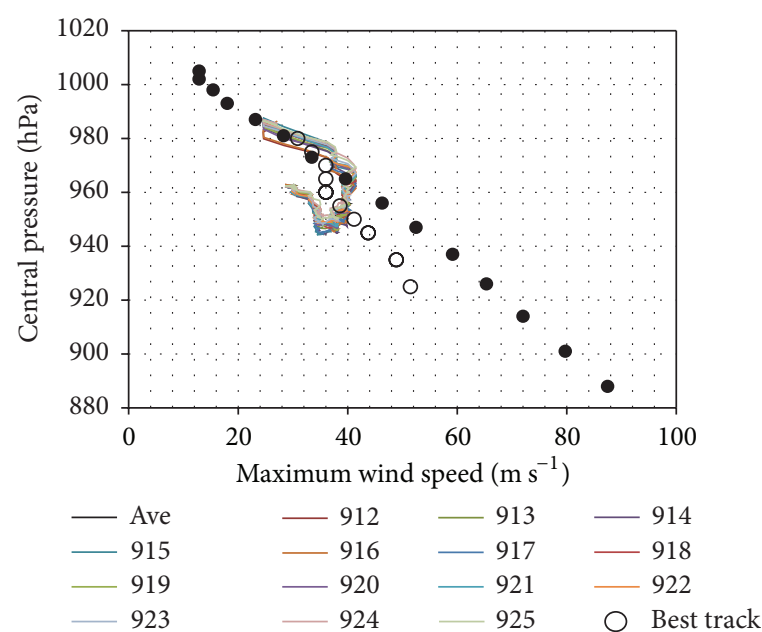

- Koba 1990

(c)

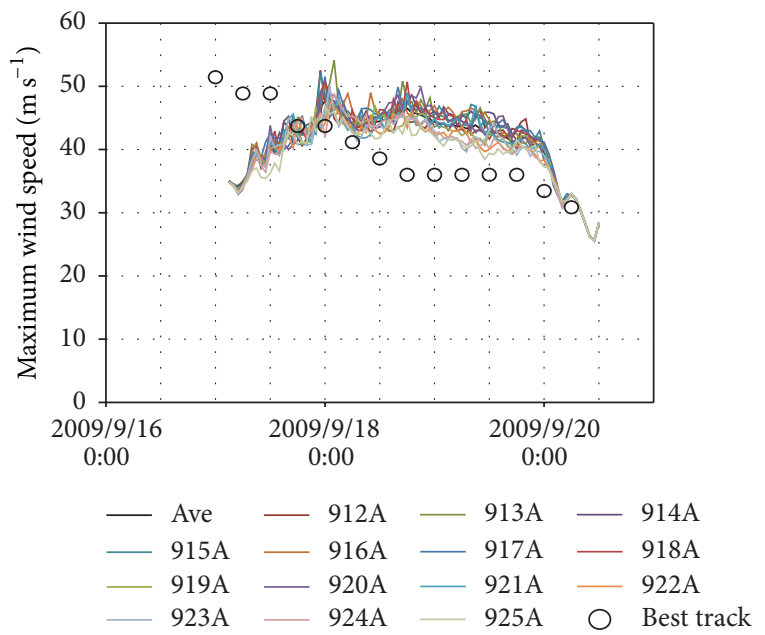

(e)

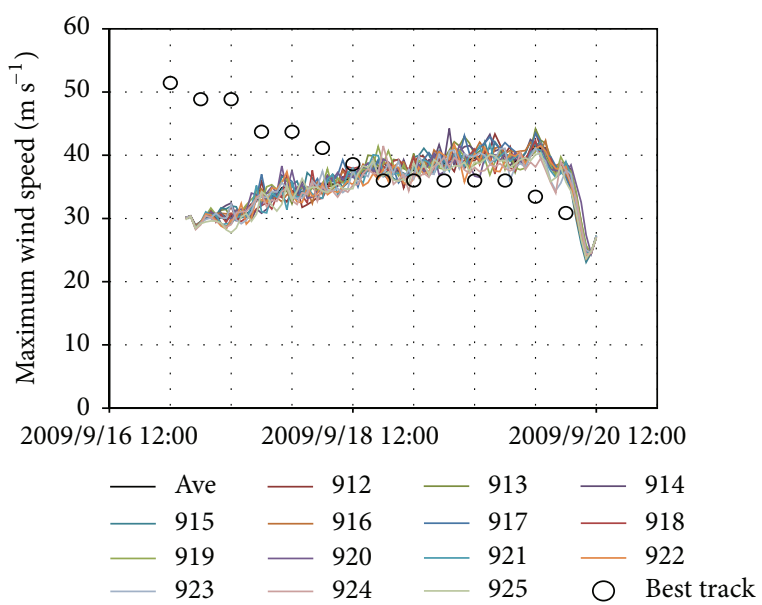

(b)

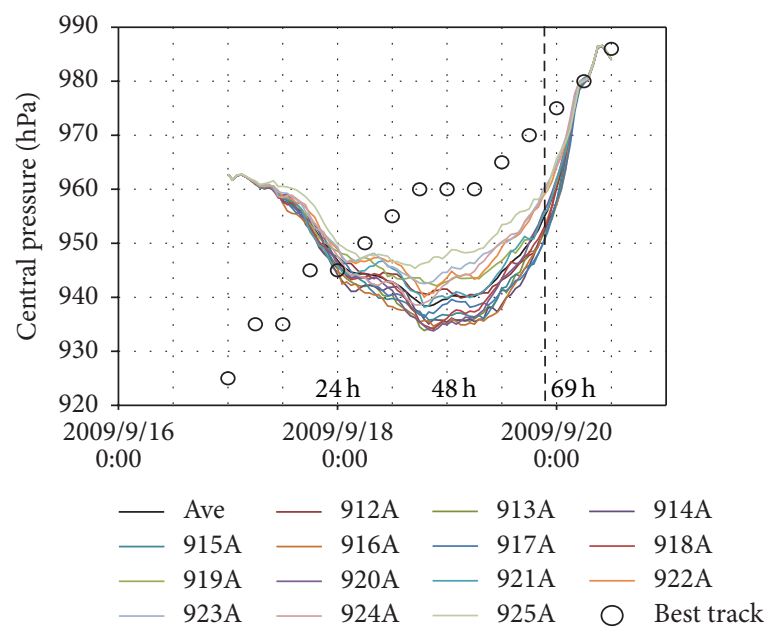

(d)

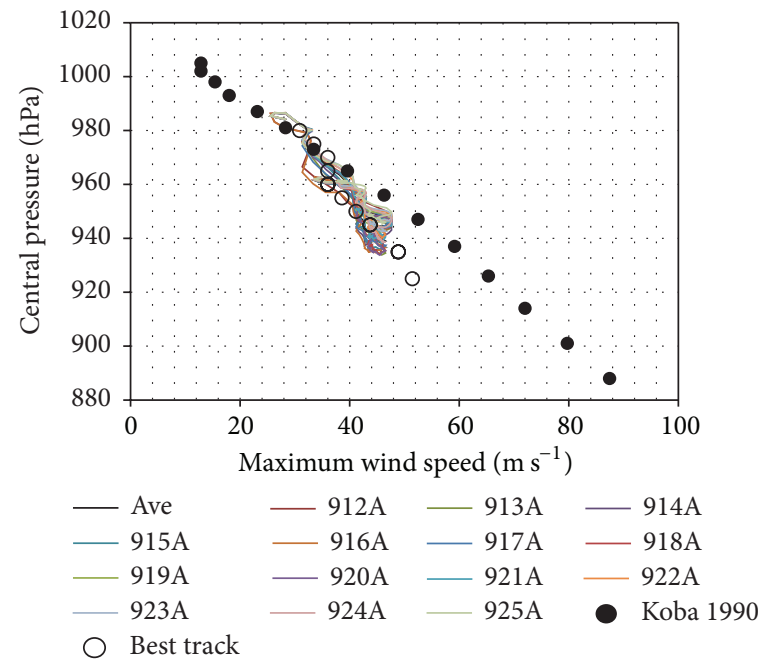

(f)

FIGURE 4: Time series of (a) central pressure and (b) maximum wind speed, showing the six-hourly best-track values, the hourly value in each simulation, and the mean hourly simulated value of the 14 simulations. Integration times at $24 \mathrm{~h}, 48 \mathrm{~h}$, and $69 \mathrm{~h}$ are included in the intensification, mature, and decaying phases, respectively. (c) The wind-pressure relationship simulated by the coupled model in each experiment and in the best-track data. The relationship proposed by Koba et al. [30] is shown for comparison. (d)-(f) Same as (a)-(c), except showing the simulation results of the uncoupled atmosphere model. 

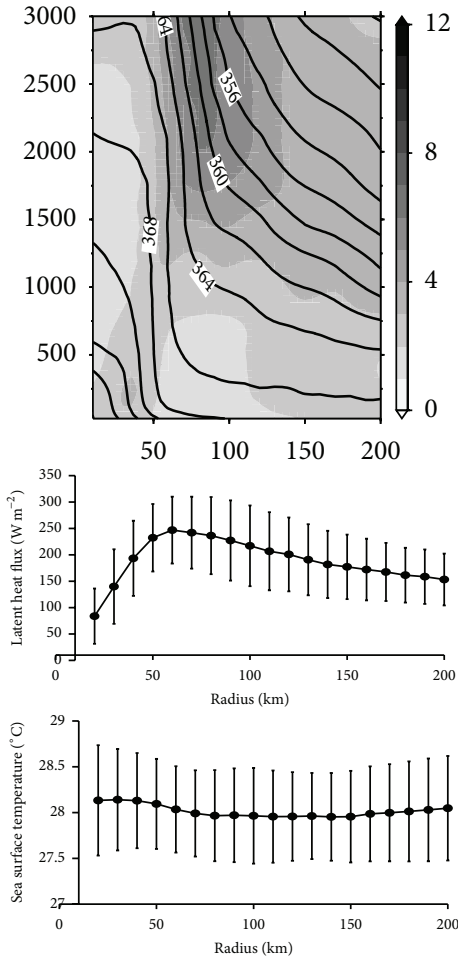

(a)
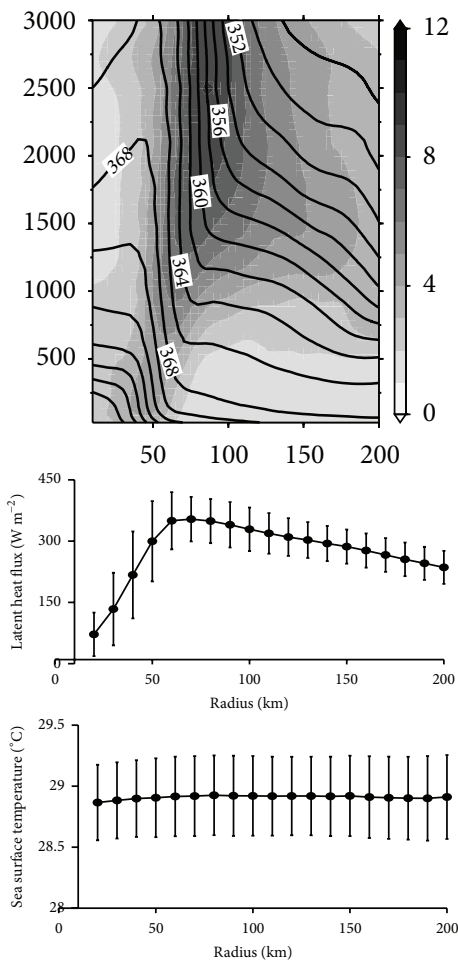

(d)
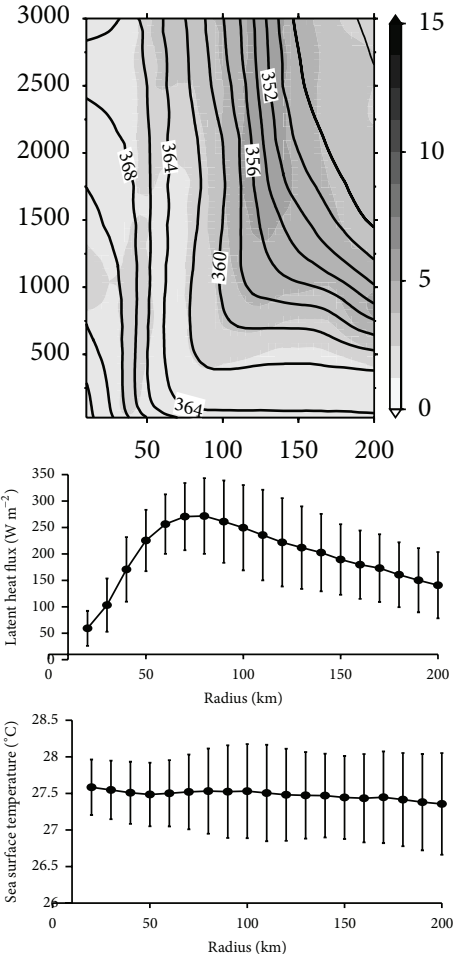

(b)
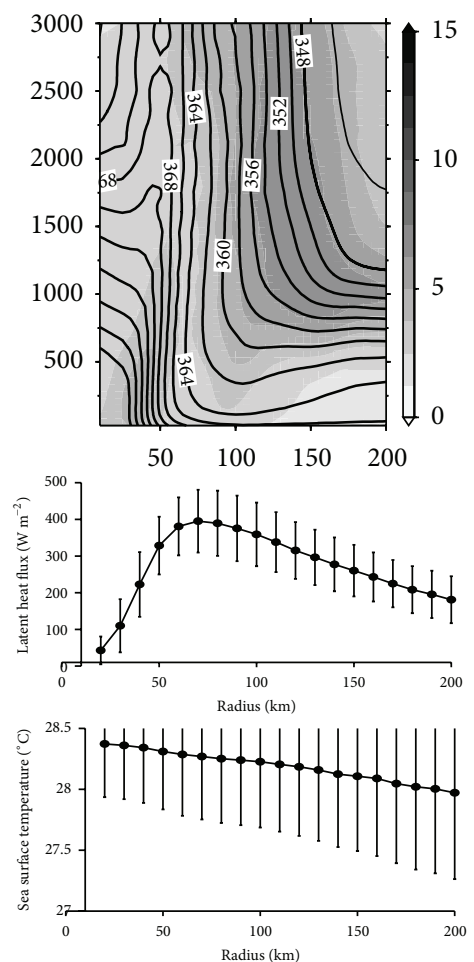

(e)
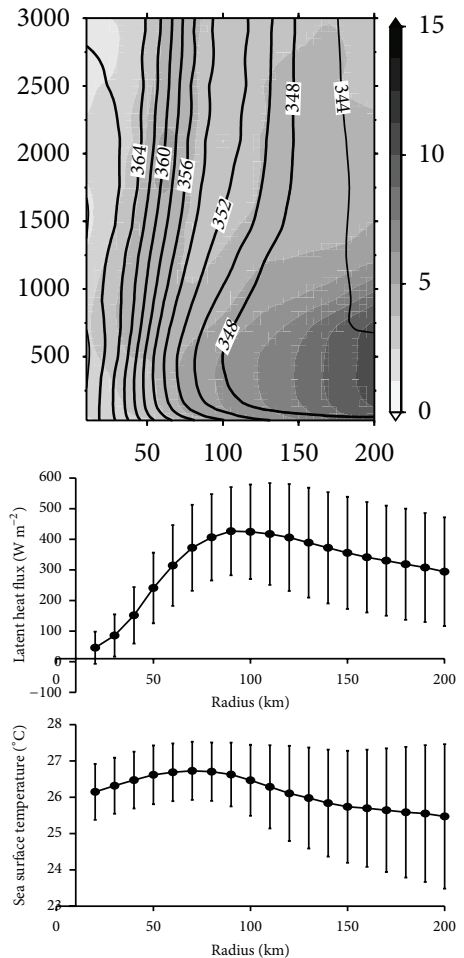

(c)
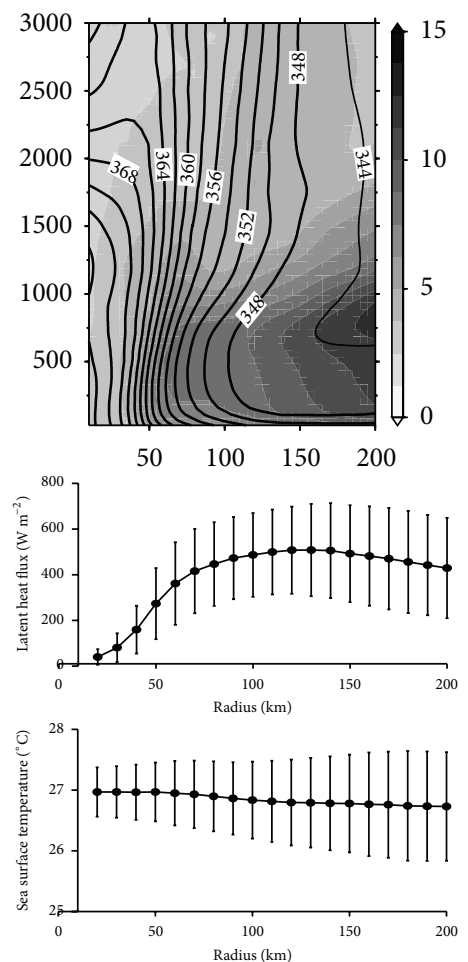

(f)

FIGURE 5: Vertical profiles of the axisymmetric mean equivalent potential temperature (contours; contour interval, $2 \mathrm{~K}$ ) of all experiments and standard deviations (shading) (upper panels), the axisymmetric mean latent heat flux (line) and standard deviations (vertical bars) (middle panels), and the axisymmetric mean sea surface temperature (line) and standard deviations (vertical bars) at (a) $24 \mathrm{~h}$, (b) $48 \mathrm{~h}$, and (c) $69 \mathrm{~h}$. The distance from the center of the simulated typhoon (i.e., the TC radius) is shown on the horizontal axis. (d)-(f) Same as (a)-(c), but showing the results of simulations with the uncoupled atmosphere model. The unit of the vertical axis is $\mathrm{m}$. 
In the uncoupled NHM results, within $200 \mathrm{~km}$ from the center of the typhoon, SST is uniformly $\sim 29^{\circ} \mathrm{C}$, and at $24 \mathrm{~h}$ and $48 \mathrm{~h}$, the axisymmetric mean latent heat flux within radii of about $50-100 \mathrm{~km}$ is $1.4-1.6$ times that calculated by the coupled model (compare Figures 5(d) and 5(e) with Figures 5(a) and 5(b)). At $69 \mathrm{~h}$ (Figure 5(f)), the axisymmetric mean latent heat flux between $\sim 100$ and $200 \mathrm{~km}$ from the typhoon center is remarkably higher than that simulated by the coupled model (Figure 5(c)). However, the vertical profiles of equivalent potential temperature calculated by the uncoupled NHM are similar to those calculated by the coupled model in all three phases. In the uncoupled NHM results, however, the horizontal gradient of the axisymmetric mean equivalent potential temperature is steeper within radii of around $50-100 \mathrm{~km}$ because of higher SST and latent heat flux compared with the coupled model results. The uncoupled model results thus confirm that the impact of variations in preexisting oceanic conditions on the axisymmetric structure of the simulated Choi-wan differs depending on the phase of the simulated typhoon. Therefore, we focus below on the coupled model simulation results.

At $24 \mathrm{~h}$, the axisymmetric mean specific humidity of the 14 simulations exceeds $20 \mathrm{~g} \mathrm{~kg}^{-1}$ below the height of $500 \mathrm{~m}$ (Figure 6(a)), and the area of high mean specific humidity is mostly below $1000 \mathrm{~m}$, within the inflow layer. As with equivalent potential temperature (Figure 5(a)), standard deviations of specific humidity are highest above $1500 \mathrm{~m}$ within radii of around 50-100 km (Figure 6(a)), where later the eyewall is robust at $48 \mathrm{~h}$. The simulated rapid decreases in mean specific humidity around the radii of $50-100 \mathrm{~km}$ are attributable to downward airflow induced by condensational heating in the eyewall and possibly also to momentum mixing across the inner edge of the eyewall [32].

At $48 \mathrm{~h}$ (Figure 6(b)), the decrease in mean specific humidity outside the radius of $50 \mathrm{~km}$ is more rapid, and the area of maximum mean inflow area shifts outward from its location at $24 \mathrm{~h}$. Moreover, the area of high standard deviations of specific humidity is at lower altitude $(\sim 1000 \mathrm{~m})$ compared with its position at $24 \mathrm{~h}$ (Figure 6(a)), and it is outward of the area of maximum mean inflow (Figure 6(b)). High standard deviations of specific humidity are associated with decreased mean specific humidity and dry air formation, caused by the downward airflow accompanied by evaporative cooling [33] (Figure 5(b)).

At $69 \mathrm{~h}$, the horizontal gradient of mean specific humidity steepens at $50 \mathrm{~km}$, the inner edge of the inflow area (Figure $6(\mathrm{c})$ ). The area of maximum mean inflow is at radii of around $100-150 \mathrm{~km}$, reflecting an outward shift from its position at $48 \mathrm{~h}$ (Figure 6(b)). Consistent with the equivalent potential temperature results (Figure 5(c)), standard deviations of specific humidity are high at radii larger than $150 \mathrm{~km}$ and at heights below $1000 \mathrm{~m}$ (Figure 6(c)).

The overlap of the area of maximum mean inflow with high mean specific humidity values (Figure 6(a)) means that the transport of moisture inward toward the inner core of the simulated typhoon is contributing to the formation of the typhoon's axisymmetric structure. By contrast, during the decaying phase, the mean specific humidity is low in the area of maximum mean inflow (Figure 6(c)), so little moisture is being transported inward during that phase.

The horizontal specific humidity flux is calculated by multiplying the specific humidity by the horizontal wind speed (including both radial and tangential winds). In general, the area of maximum mean tangential wind speed is higher than the area of the maximum axisymmetric mean horizontal specific humidity flux (Figures 6(d), 6(e) and 6(f)), but, whereas their positions are almost the same at $24 \mathrm{~h}$ (Figure $6(\mathrm{~d})$ ) and at $48 \mathrm{~h}$ (Figure 6(e)), they are clearly different at $69 \mathrm{~h}$ (Figure 6(f)). At $69 \mathrm{~h}$, the area of high mean horizontal specific humidity flux is at a lower altitude and closer to the center of the simulated typhoon than that at $24 \mathrm{~h}$ and $48 \mathrm{~h}$ because the mean specific humidity is higher where mean horizontal specific humidity flux is highest (Figure 6(c)).

The standard deviations of radial flow together with those of tangential flow among the 14 simulations (Figures 6(g), 6(h) and 6(i)) show how preexisting oceanic conditions affect the dynamics of the simulated typhoon. At $24 \mathrm{~h}$, standard deviations of radial flow are high around the radius of $50 \mathrm{~km}$ below $1000 \mathrm{~m}$ (Figure $6(\mathrm{~g})$ ), corresponding to the position of the innermost edge of the area of maximum mean inflow (Figure 6(a)), whereas standard deviations of tangential air flow are high where the gradient of mean cyclonic tangential flow is steep (Figure 6(d)). Therefore, the standard deviations of both radial and tangential flows are high where the wind gradient is unbalanced. This result shows that preexisting oceanic conditions have a remarkable impact on where a supergradient wind flow is generated, but not on the location of a radially inward jet $[34,35]$. In addition, the rapid deceleration of radial flow inside the eyewall and the associated upward air motion during the intensification phase is also affected by preexisting oceanic conditions.

At $48 \mathrm{~h}$, standard deviations of radial flow are high above $1500 \mathrm{~m}$ at radii of around $50-100 \mathrm{~km}$ (Figure 6(h)), showing the impact of preexisting oceanic conditions on the outflow layer at that time. The area where standard deviations of tangential flow are high, which includes the area where standard deviations of radial flow are high, coincides with the region where the mean cyclonic tangential flow gradient is steep (Figure 6(e)). Both these areas slant outward with height from the typhoon center. These results suggest that, unlike their effect during the intensification phase, during the mature phase, preexisting oceanic conditions affect the axisymmetric slantwise structure of the simulated typhoon through changes in dynamics within the inner core of the typhoon.

At $69 \mathrm{~h}$, standard deviations of radial flow are high below $1000 \mathrm{~m}$ at radii of around $75-175 \mathrm{~km}$ (Figure 6(i)), which is the position of a radially inward jet (Figure 6(c)). The area of high standard deviations of tangential flow is at around 500$1000 \mathrm{~m}$ and inward of the area of high standard deviations of radial flow. In addition, both areas show a greater outward slant with height from the typhoon center than those at $48 \mathrm{~h}$.

Standard deviations of the horizontal specific humidity flux are high at radii of around $50-100 \mathrm{~km}$ and altitudes of around 1000-2000 m particularly during the intensification and mature phases (Figures 6(d) and 6(e)), which appears above the strongest tangential flow. This relative location suggests that TC intensity may be related to the horizontal 


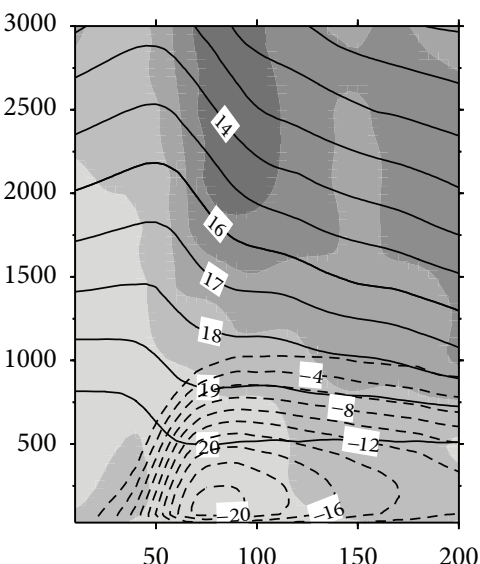

(a)

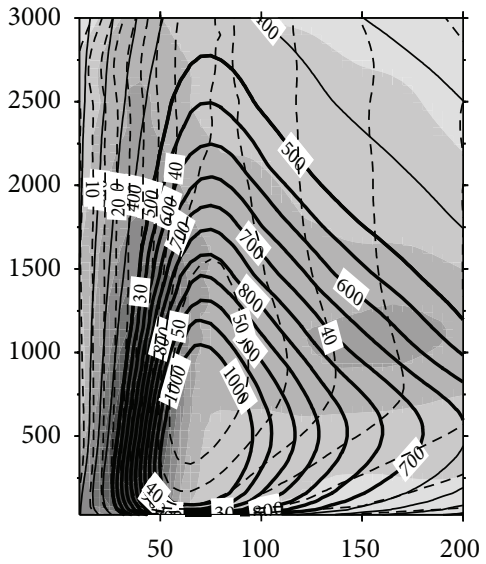

(d)

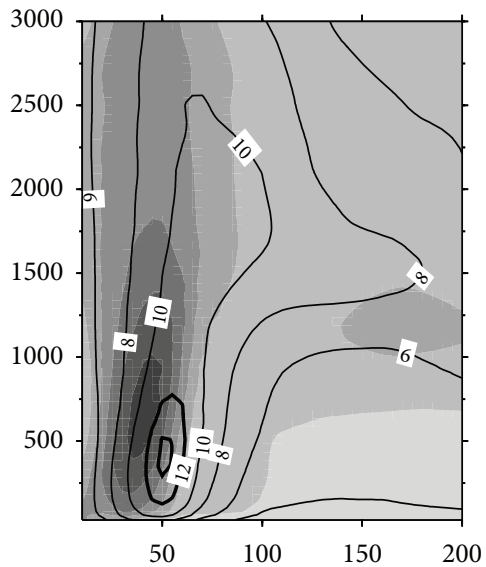

(g)

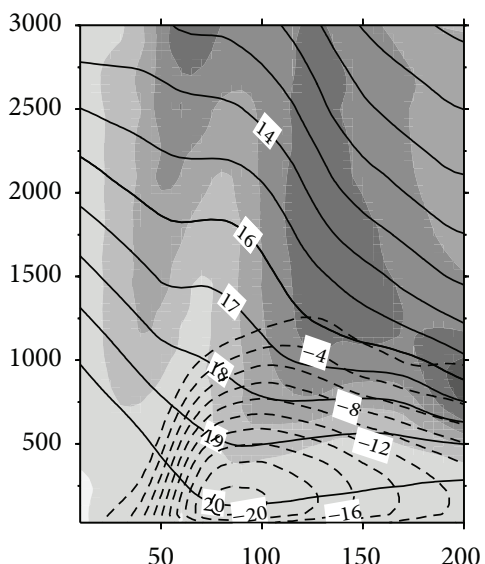

(b)

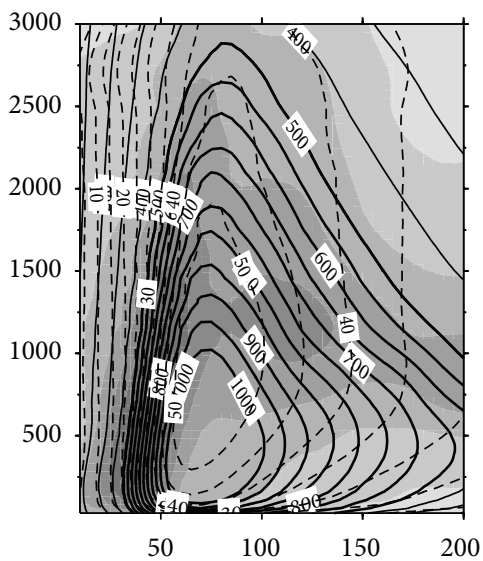

(e)

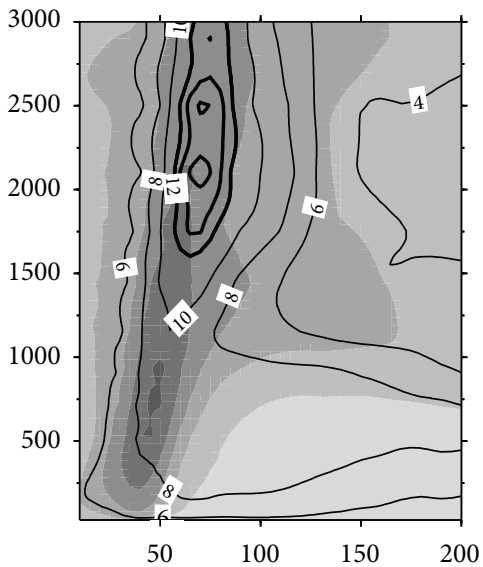

(h)

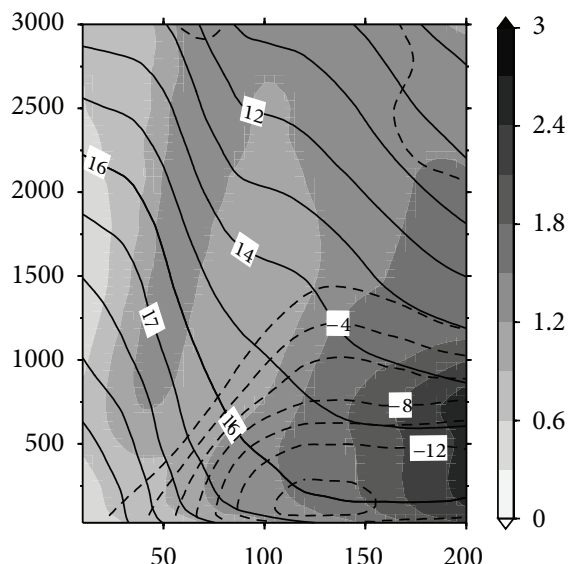

(c)

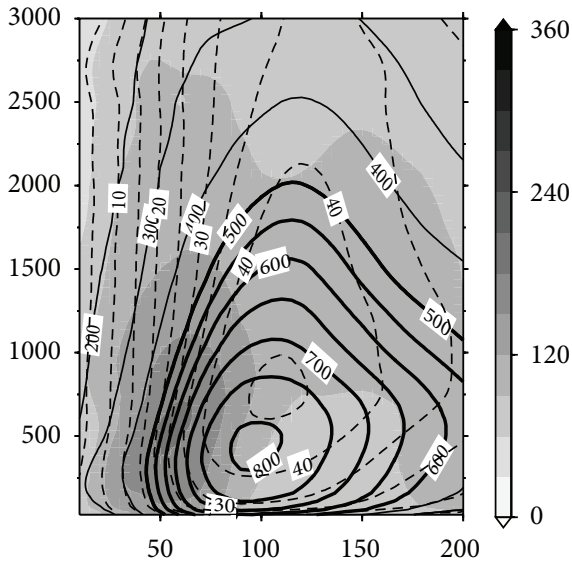

(f)

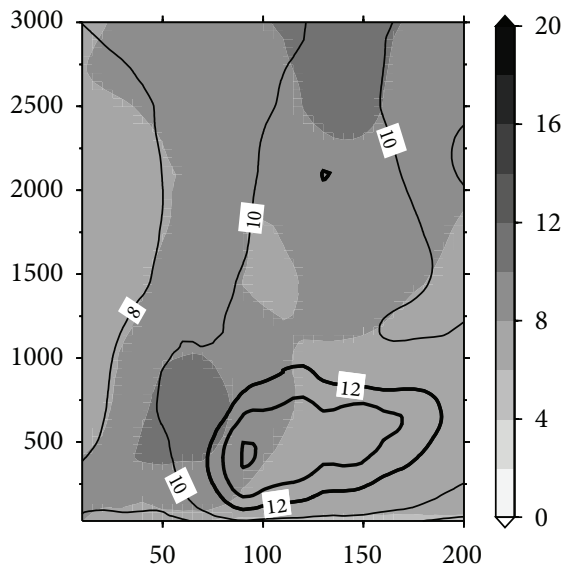

(i)

FIGURE 6: $(\mathrm{a}-\mathrm{c})$ Vertical profiles of the axisymmetric mean specific humidity (solid contours, contour interval $1 \mathrm{~g} \mathrm{~kg}^{-1}$ ) of the 14 simulations, the standard deviations of all experiments, and radial flow (dashed contours, contour interval $2 \mathrm{~m} \mathrm{~s}^{-1}$, negative sign indicates inflow) at (a) $24 \mathrm{~h}$, (b) $48 \mathrm{~h}$, and (c) $69 \mathrm{~h}$. (d-f) Vertical profiles of the axisymmetric mean horizontal specific humidity flux (solid contours, contour interval 100 or $50 \mathrm{~g} \mathrm{~m}^{-2} \mathrm{~s}^{-1}$ ) of the 14 simulations, the standard deviations of all experiments (shading), and tangential flow (dashed contours, contour interval $5 \mathrm{~m} \mathrm{~s}^{-1}$, positive sign indicates cyclonic flow) at (d) $24 \mathrm{~h}$, (e) $48 \mathrm{~h}$, and (f) $69 \mathrm{~h}$. (g-i) Vertical profiles of standard deviations of radial flow (contours) and of tangential flow (shading) among the 14 simulations at (g) $24 \mathrm{~h}$, (h) $48 \mathrm{~h}$, and (i) $69 \mathrm{~h}$. At values below $12 \mathrm{~m} \mathrm{~s}^{-1}$ (thin contours), the contour interval is $2 \mathrm{~m} \mathrm{~s}^{-1}$, and at values above $12 \mathrm{~m} \mathrm{~s}^{-1}$ (thick contours), it is $1 \mathrm{~m} \mathrm{~s}^{-1}$. The unit of the vertical axis is $\mathrm{m}$. 


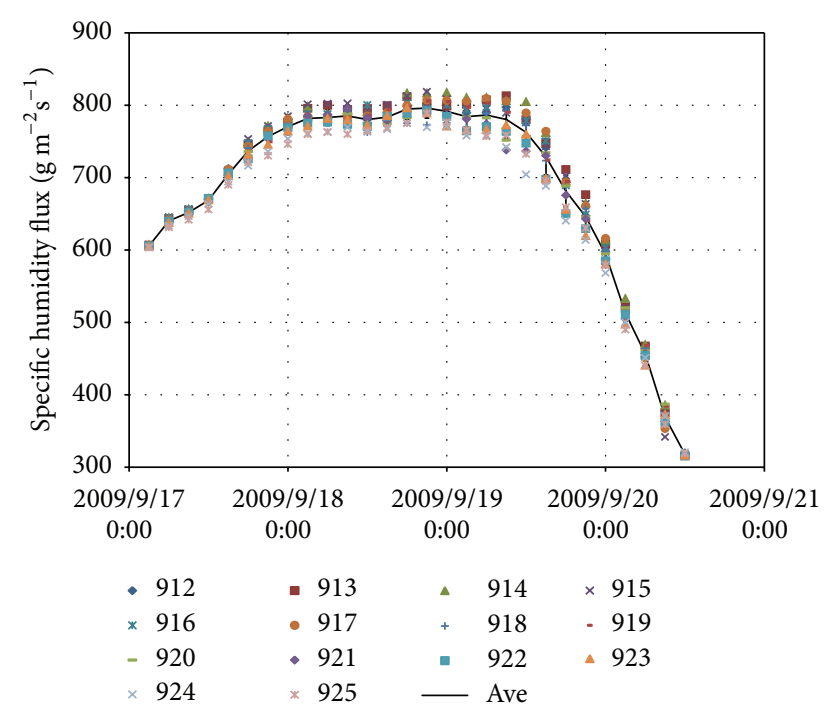

FIGURE 7: Time series of the mean horizontal specific humidity flux of the 14 simulations averaged over the area between altitudes of 20 to $2110 \mathrm{~m}$ (corresponding to model levels 2 to 13 ) and between radii of 50 and $150 \mathrm{~km}$ from the maximum wind speed. The values of each experiment are shown along with the average of the 14 experiments.

specific humidity flux as well as to the TC heat content (i.e., the oceanic heat content from the surface to the depth of the $26^{\circ} \mathrm{C}$ isotherm [36-38]). Therefore, we examine the relationship between the mean horizontal specific humidity flux and the simulated central pressure and maximum wind speed of Choi-wan (shown in Figure 4).

The mean specific humidity flux of the 14 simulations increases during the first $24 \mathrm{~h}$ of integration (Figure 7), probably because the supply of moisture from the ocean through vertical advection and stretching increases, as a result of the release of filamentation, the formation of mesovortices, and vortex merger events [37, 39]. After the intensification phase, the mean specific humidity flux of $\sim 800 \mathrm{~g} \mathrm{~m}^{-2} \mathrm{~s}^{-1}$ is maintained during the mature phase because the supply of moisture from the ocean decreases once a warm core is established at the typhoon's center [37, 39]. After $60 \mathrm{~h}$, however, the mean specific humidity flux rapidly decreases. Thus, the evolution of the axisymmetric mean specific humidity flux is inversely correlated with the evolution of the simulated central pressure (Figure 4(a)), and this correlation is high $\left(r^{2}=0.96\right)$ (Figure 8(a)). Therefore, the horizontal specific humidity flux is a potential new metric for predicting TC central pressure. By contrast, the relationship between the simulated maximum wind speed and the axisymmetric mean horizontal specific humidity flux depends on the phase of the simulated typhoon (Figure 8(b)). This result may reflect the different effect of preexisting oceanic conditions on radial flow and tangential winds among phases (Figures 6(g), 6(h) and 6(i)), which means that their effect on the wind-pressure relationship also differs among the TC phases (Figure 4(c)).

3.3. Impact of Initial Conditions on Horizontal Fields in the Atmosphere and Ocean. Wada and Usui [36] reported that coupling the multilayer ocean model to NHM affected the simulation of the eyewall of Typhoon Hai-Tang (2005) during the intensification phase, whereas variations in preexisting oceanic conditions affected the simulation of both the spiral rainbands and the amplitude of TC-induced sea surface cooling. Here, we describe the impacts of variations in preexisting oceanic conditions on simulated horizontal fields of the atmosphere and ocean.

Weather charts, obtained from the website of the Japan Meteorological Agency (http://www.data.jma.go.jp/fcd/ yoho/hibiten/index.html), of the Kuroshio Extension region during the passage of Typhoon Choi-wan (Figure 9) show a stationary front north of the typhoon at 0000 UTC on September 18 (Figure 9(a)). The northern edge of the northeastward moving typhoon reached the stationary front at 0000 UTC on September 19 (Figure 9(b)) and at 0000 UTC on September 20 (Figure 9(c)), when the typhoon was over the front, it transitioned to an extratropical cyclone.

At $24 \mathrm{~h}$ (Figure 10(a)), mean $10 \mathrm{~m}$ wind speeds of the 14 simulations are high around the typhoon. Interestingly, standard deviations of the $10 \mathrm{~m}$ wind speed are relatively high over the stationary front even though the mean $10 \mathrm{~m}$ wind speed there is relatively weak. By contrast, high standard deviations of the $10 \mathrm{~m}$ wind speed are seen only near the center of the typhoon at $24 \mathrm{~h}$. At $48 \mathrm{~h}$ (Figure 10(b)), the area of relatively high $10 \mathrm{~m}$ wind speeds around the typhoon enlarges, and higher standard deviations of the $10 \mathrm{~m}$ wind speed are seen. The standard deviations over the stationary front, however, are still conspicuously higher than those around the typhoon. At $69 \mathrm{~h}$ (Figure 10(c)), the typhoon is crossing the stationary front; at this time, the axisymmetric horizontal distribution of the mean $10 \mathrm{~m}$ wind speed around the typhoon becomes asymmetric, and the standard deviations are high both around the typhoon and along the stationary front. Among the 14 simulations, standard deviations of both SST (Figures 11(a), 11(b) and 11(c)) and $20 \mathrm{~m}$ air temperature (Figures 11(d), $11(\mathrm{e})$ and 11(f)) are high along the stationary front, indicating that variations in the $20 \mathrm{~m}$ air temperature are closely related to SST variations in this area.

At $24 \mathrm{~h}$ and $48 \mathrm{~h}$ (Figures 12(a) and 12(b)), the mean latent heat flux of the 14 simulations is relatively high around the typhoon, where mean $10 \mathrm{~m}$ wind speeds are high (Figures 10(a) and 10(b)), whereas standard deviations of latent heat flux are relatively low there. In addition, at these time points, standard deviations are low over the stationary front, but they become high at $69 \mathrm{~h}$, both around the typhoon and over the stationary front (Figure 12(c)). The area where the standard deviations of latent heat flux are high agrees well with the area with high standard deviations in SST (Figure 11(c)).

At $24 \mathrm{~h}$ and $48 \mathrm{~h}$ (Figures 12(d) and 12(e)), mean hourly precipitation and its standard deviations are both high around the typhoon and over the stationary front. At $69 \mathrm{~h}$ (Figure 12(f)), mean hourly precipitation and its standard deviation are also high along the stationary front, but the area with high standard deviations is narrow compared with the areas of high standard deviations of SST and latent heat flux. These differences show that preexisting oceanic conditions affect the simulated horizontal fields of the atmosphere and ocean differently between the typhoon and the stationary 


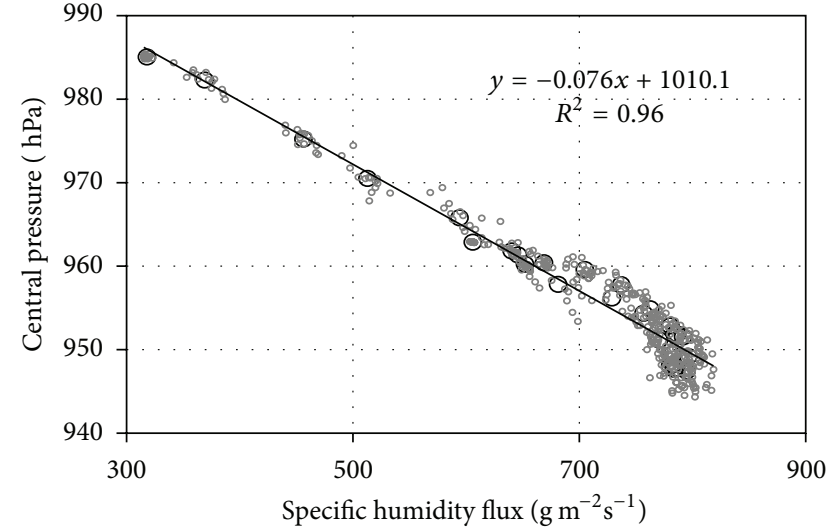

(a)

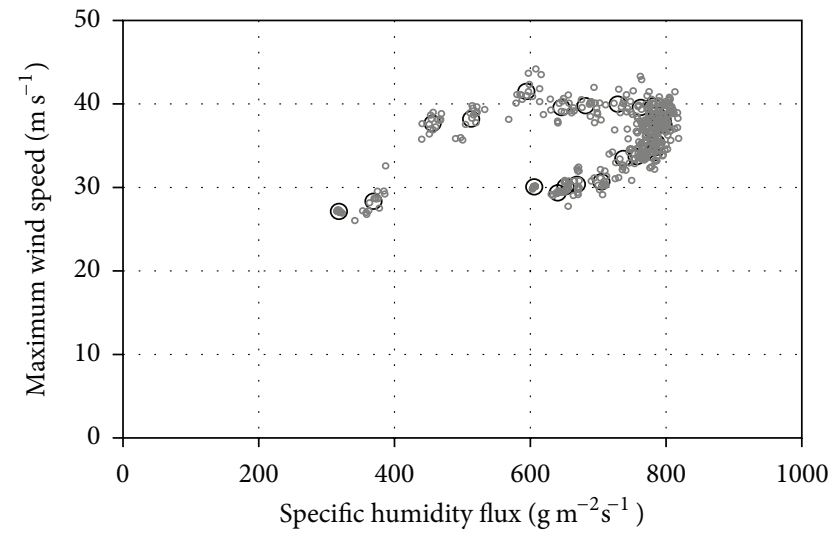

(b)

FIGURE 8: (a) Relationships the horizontal specific humidity flux and the simulated central pressure in the 14 experiments (gray circles) and between their averages and (b) relationships between the horizontal specific humidity flux and the simulated maximum wind speed in the 14 experiments (gray circles) and between their averages.

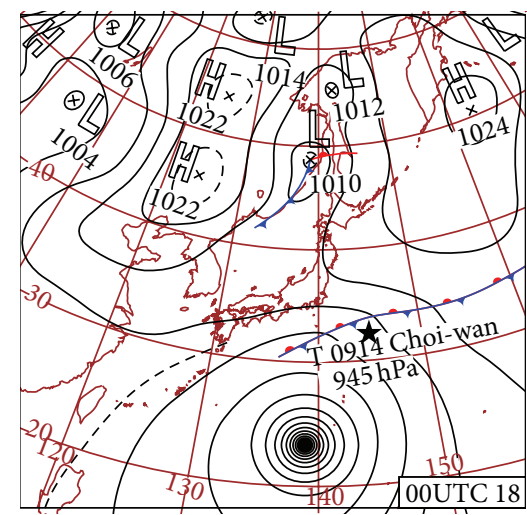

(a)

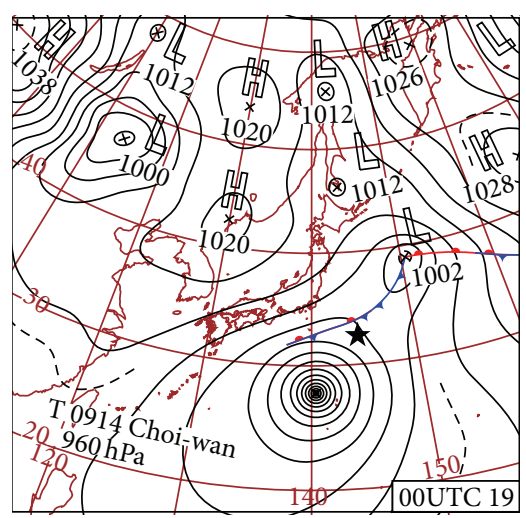

(b)

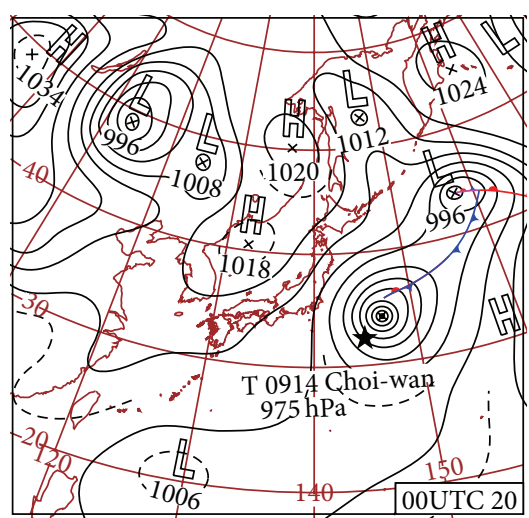

(c)

FIGURE 9: Weather maps from the Japan Meteorological Agency for (a) 0000 UTC on September 18, (b) 0000 UTC on September 19, and (c) 0000 UTC on September 20. A star mark indicates the location of the KRO buoy.

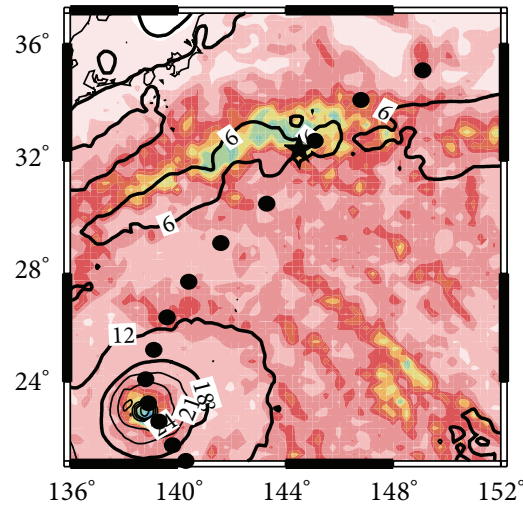

(a)

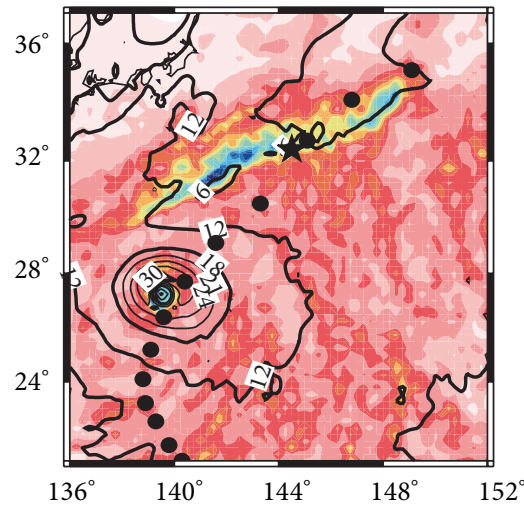

(b)

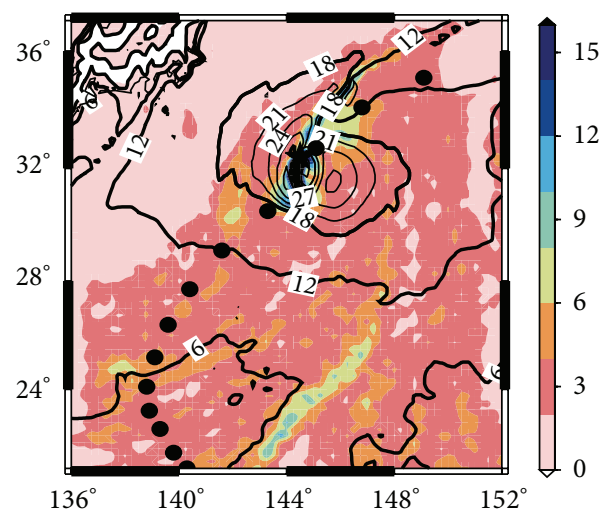

(c)

Figure 10: Horizontal distributions of the simulated $10 \mathrm{~m}$ wind speed (contours, contour intervals $6 \mathrm{~m} \mathrm{~s}^{-1}$ and $3 \mathrm{~m} \mathrm{~s}^{-1}$ ) and its standard deviation (shading) at (a) $24 \mathrm{~h}$, (b) $48 \mathrm{~h}$, and (c) $69 \mathrm{~h}$. The star shows the location of the KEO moored buoy. 


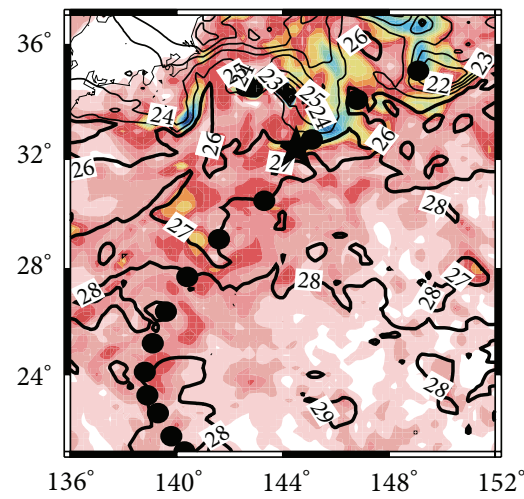

(a)

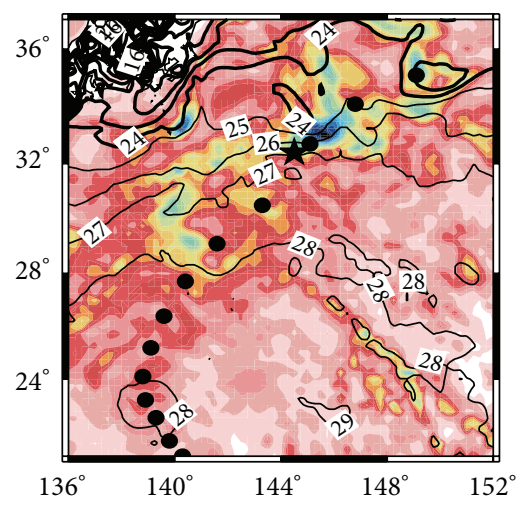

(d)

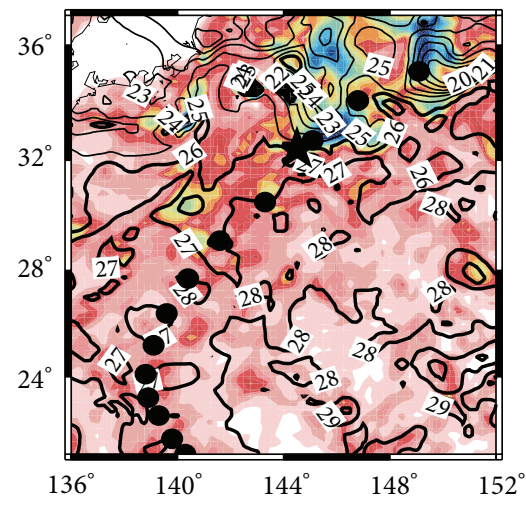

(b)

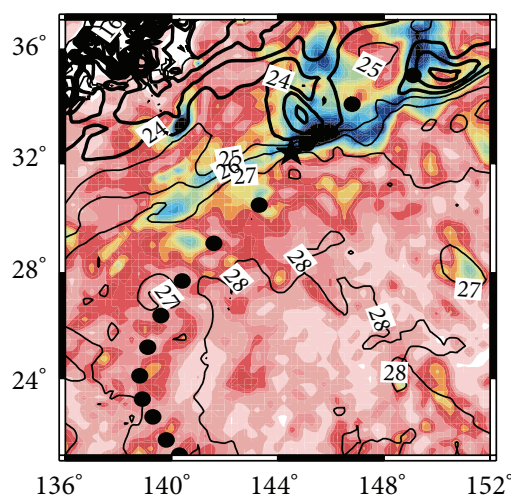

(e)

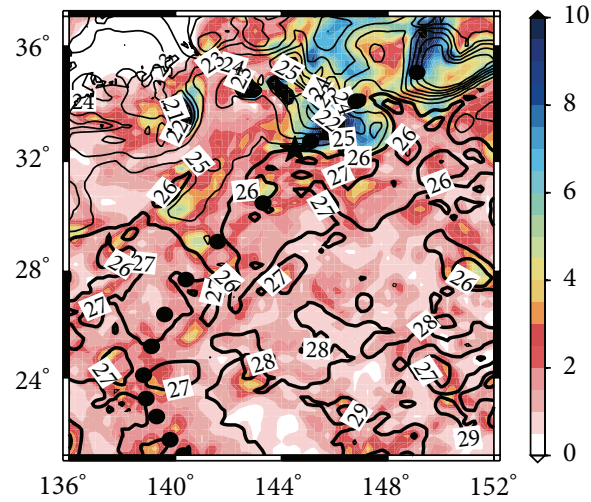

(c)

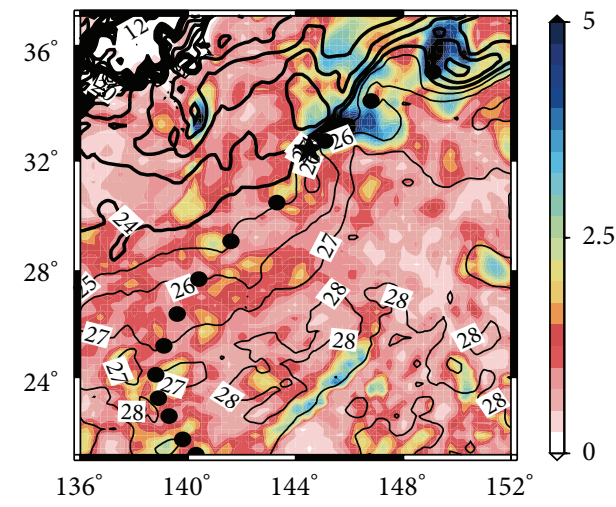

(f)

Figure 11: Same as Figure 10 except for $(\mathrm{a}-\mathrm{c})$ sea surface temperature and (d-f) air temperature at $20 \mathrm{~m}$ height at (a, d) $24 \mathrm{~h},(\mathrm{~b}, \mathrm{e}) 48 \mathrm{~h}$, and (c, f) $69 \mathrm{~h}$.

front. In addition, in areas where the variations in the $10 \mathrm{~m}$ wind speed and hourly precipitation are small, the distributions of the variations in the $10 \mathrm{~m}$ wind speed agree well with those in hourly rainfall, whereas the distributions of the variations in SST correspond to those in latent heat flux, and, thus, to those in the $20 \mathrm{~m}$ air temperature in the three times $(24 \mathrm{~h}, 48 \mathrm{~h}$, and $69 \mathrm{~h})$. Over the stationary front, the impact of preexisting oceanic conditions on hourly precipitation is closely related to that on the $10 \mathrm{~m}$ wind speed, whereas their impact on the $20 \mathrm{~m}$ air temperature is greatly affected by that on SST through the latent heat flux.

Over the stationary front, standard deviations of hourly rainfall are high on the northern side of the simulated TC track (Figure 12(d)), and the simulated SST is relatively lower there than that on the southern side of the track (Figure 11(a)). High variations in hourly rainfall under low SST differs from a rainband detected over the southern portion of the Kuroshio in the East China Sea in winter, where SST is relatively high [40].

3.4. Validation of Numerical Simulation Results at the KEO Buoy Site. We validated the numerical simulations by comparing observations of sea level pressure, $10 \mathrm{~m}$ air temperature, and SST obtained at the KEO moored buoy site $\left(32.4^{\circ} \mathrm{N}\right.$, $144.5^{\circ} \mathrm{E}$ ) [41] with the corresponding simulated results (Figure 13). For the purposes of the validation, we assumed that, in accordance with similarity theory, air temperature was constant within the surface boundary layer.

The validation results show a 3-h delay of the simulated minimum central pressure compared with the observation (Figure 13(a)). This delay is not affected by variations in preexisting oceanic conditions, although the amplitude of the minimum central pressure does depend on preexisting oceanic conditions (Figure 13(a)). Simulated $20 \mathrm{~m}$ air temperatures in experiments 0921, 0922, 0923, 0924, and 0925 differ substantially from the observations and from the simulation results obtained using initial conditions on September 20 or before (Figure 13(b)). For simulations with initial conditions from September 21 or after, simulated SST values are low compared with observations (Figure 13(c)). Thus, the simulated SST and the simulated $20 \mathrm{~m}$ air temperature show similar patterns. The validation results show that changing the preexisting oceanic conditions does not improve the simulation of sealevel pressure, air temperature, or SST at the KEO buoy site. This result may be related to the result that the impact of preexisting oceanic conditions on the track simulations is small.

\section{Discussion}

This study showed that, similar to the effect of TC-induced sea surface cooling, the effect of preexisting oceanic conditions on TC simulations depends on the phase of the TC. 


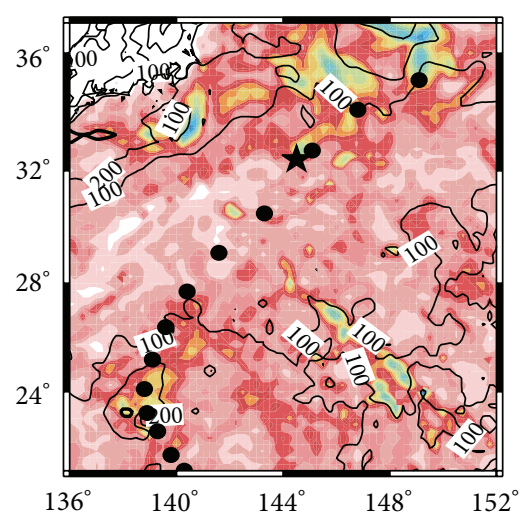

(a)

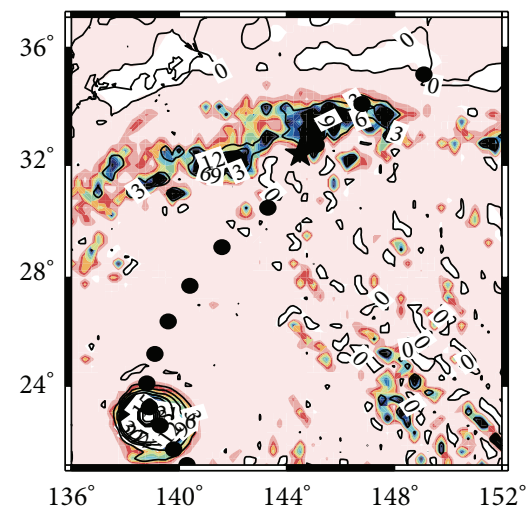

(d)

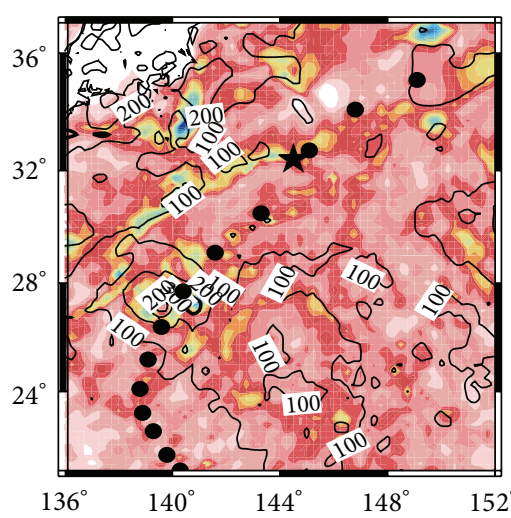

(b)

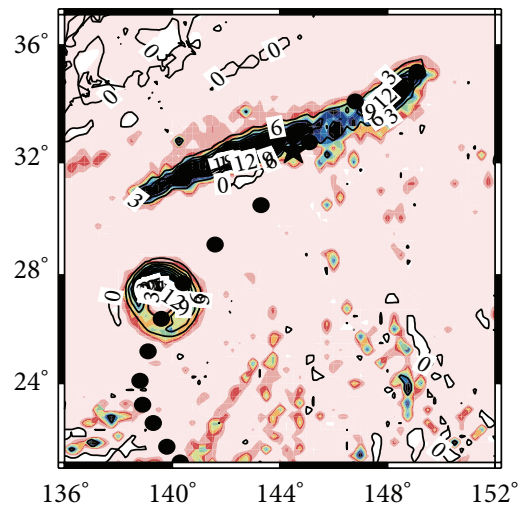

(e)

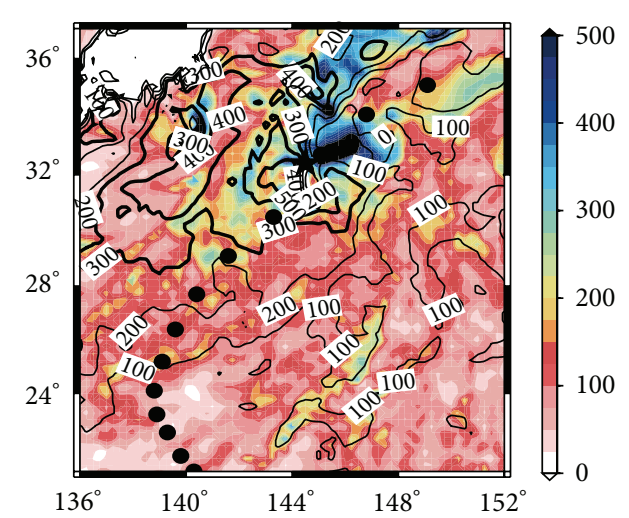

(c)

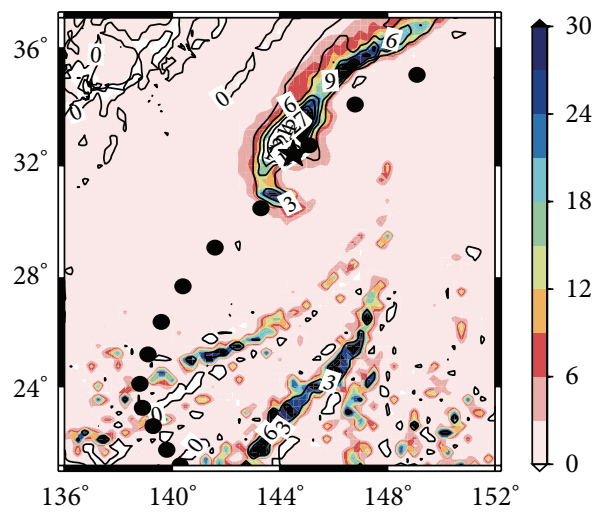

(f)

FIGURE 12: Same as Figure 10 except for $(\mathrm{a}-\mathrm{c})$ sea to air latent heat flux and (d-f) hourly precipitation at (a, d) 24 h, (b, e) 48 h, and (c, f) 69 h.

Moreover, we showed for the first time that the inner core structure of a TC can be affected by preexisting oceanic conditions through the supergradient process during the intensification phase and through an outward shifting of the eyewall with height accompanied by oblique convection during the mature phase. These changes to the inner core structure in response to variations in preexisting oceanic conditions in simulations performed with the coupled model are similar to those in simulations performed with the uncoupled NHM, indicating that the changes are not a response to the ocean coupling (Figure 5). Furthermore, we found that the impact of preexisting oceanic conditions on the transition to an extratropical cyclone within the inflow boundary layer, where mean specific humidity is relatively low, was notably greater than their impacts during the intensification and mature phases. As a result of the reduction of the inward transport of moisture, the mean horizontal specific humidity flux rapidly decreases as the simulated central pressure rises (Figures 7 and $8(\mathrm{a})$ ). A recent TC simulation study suggested that axisymmetrization of the TC enables air parcels to stay longer within the core region, which allows more heat transfer from the underlying ocean [42]. Radial and tangential flows play a role in keeping the air parcels longer within the core region. The lateral inward energy flux gives rise to energy production outside a critical radius (30-45 km in a study by Wang and $\mathrm{Xu}$ [43]) that is higher than the energy dissipation due to surface friction [43]. In the present study, the proposed horizontal specific humidity flux may be influenced by lateral inward energy flux and energy dissipation.

The simulated wind-pressure relationships (Figure 4(c)) differed depending on the phase of the simulated Choi-wan but were not affected by preexisting oceanic conditions. The simulated maximum wind speed was not significantly correlated with the mean horizontal specific humidity flux during any phases of the simulated Choi-wan (Figure 8(b)). We found good agreement of the wind-pressure relationship proposed by Koba et al. [31] with the relationship simulated by the coupled model and with the best-track wind-pressure relationship only during the decaying phase. In fact, the simulated central pressure drops excessively during the intensification phase (Figure 4(c)) compared with the best-track central pressure, even though the maximum wind speeds were relatively low during that phase. As described in Section 3.2, condensational heating due to convection in the eyewall contributed to the formation of a warm core in the eye during the intensification phase. However, the simulated pressure gradient was not steep enough to produce the maximum wind speeds anticipated by the wind-pressure relationship proposed by Koba et al. [31]. A possible reason for this difference may be the horizontal resolution of the coupled model. Kanada et al. [44] showed that the wind-pressure relationship calculated by a nonhydrostatic model with a horizontal grid 


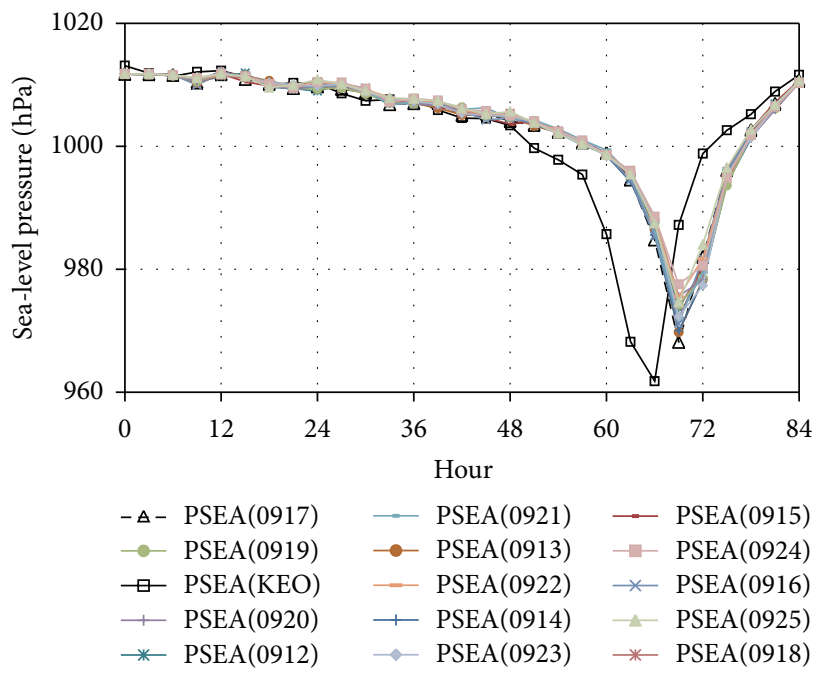

(a)

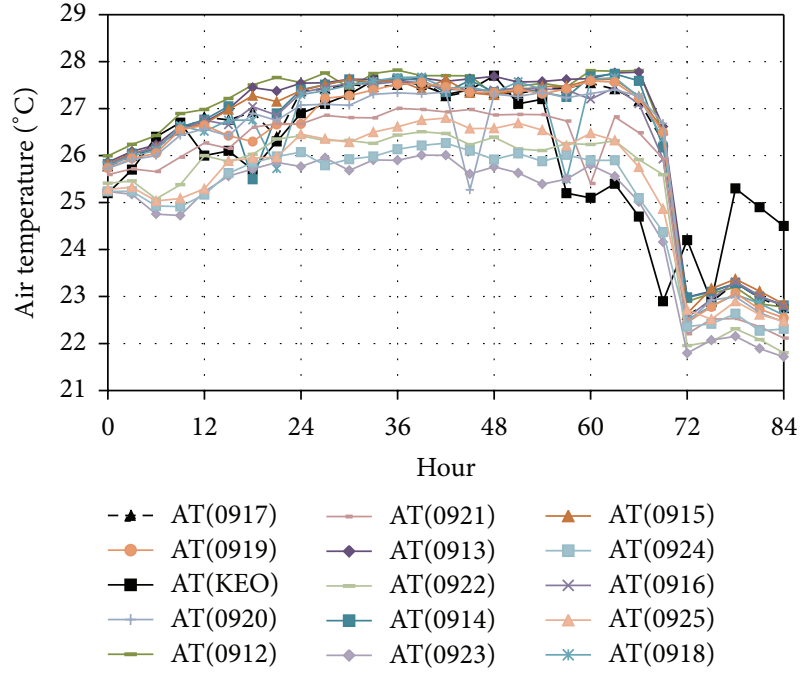

(b)

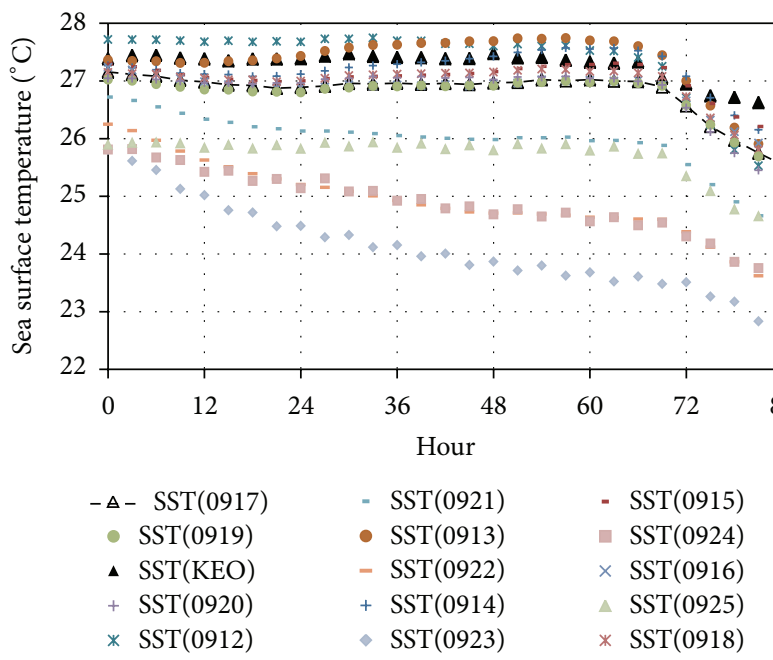

(c)

FIGURE 13: Time series of (a) observed and simulated sea level pressure in all experiments, (b) observed air temperature at $10 \mathrm{~m}$ height and simulated air temperature at $20 \mathrm{~m}$ height in all experiments, and (c) observed and simulated sea surface temperature in all experiments at $32.4^{\circ} \mathrm{N}, 144.5^{\circ} \mathrm{E}$, the location of the KEO moored buoy.

spacing of $2 \mathrm{~km}$ reproduced the empirical relationship better than the model with a horizontal grid spacing of $5 \mathrm{~km}$. However, they studied the wind-pressure relationship only during the intensification phase, whereas in the present study, we investigated the relationship during the intensification, mature, and decaying phases. Whether the dependence of the relationship on the TC phase changes according to the horizontal resolution of the model is a subject that should be explored in the future. The excessive condensational heating derived from the physical processes of the nonhydrostatic atmosphere model may explain the relative lack of progress in predicting TC intensity and changes in TC intensity [45].

In this study, we estimated the uncertainties of the effects of preexisting oceanic conditions on TC track and intensity simulations, but the uncertainties of the effect on TC track simulations need to be revised because the results are affected by the lateral boundary sponge layer setting in the nonhydrostatic atmosphere model. TC track simulations are highly sensitive to this parameter, particularly those of TCs in the mid-latitude ocean, where variations in initial atmospheric conditions affect simulations of both the TC track and TC intensity and intensity changes [39]. By contrast, variations in preexisting oceanic conditions hardly affect TC track simulations in subtropical regions [18]. TC track simulations for given atmospheric initial conditions and a given lateral boundary sponge layer width could be improved by employing ensemble perturbations to the atmospheric and oceanic fields, such as perturbations of the SST field, produced with a local ensemble transform Kalman filter (LETKF) [17]. However, the application of LETKF data assimilation to simulations with the coupled atmospherewave-ocean model used in the present study is a subject 
for future investigations. We expect that improving the TC track simulation would improve the model validation results against the KEO observations as well.

In this study, we did not validate our simulation results against observed data from locations other than the KEO buoy site because field observation data, such as direct observations by aircraft, are lacking. Therefore, in this study we could demonstrate only the sensitivity of TC simulations, including their axisymmetric structure, to preexisting oceanic conditions. In the future, we plan to use data from The Observing System Research and predictability Experiment (THORPEX) Pacific Asian Regional Campaign (TPARC) $[46,47]$ or The Impacts of Typhoons on the Ocean in the Pacific (ITOP) [48] projects to validate numerical TC simulations. At present, no research project is collecting data associated with TCs from the middle latitudes of the North Pacific, where few direct observations have been made. Such data would be useful for studies of the interaction between TCs and the Kuroshio Extension system.

\section{Conclusion}

We investigated interactions between Typhoon Choi-wan (2009) and the Kuroshio Extension system, particularly the effect of changes in preexisting oceanic conditions on a weekly time scale on those interactions, by performing 14 numerical simulations with 14 sets of oceanic initial conditions with a regional coupled atmosphere-wave-ocean model. The initial conditions were based on daily oceanic reanalysis data for September 12 to September 25, 2009, calculated by the North Western Pacific version of the Meteorological Research Institute (MRI) ocean variational estimation (MOVE) system with a horizontal grid spacing of $0.1^{\circ}$ [20]. Our conclusions are as follows.

(1) The impact of preexisting oceanic conditions on the Choi-wan's track simulation was small because the lateral boundary sponge layer width was set to a large value. Their impact on central pressure simulations and the axisymmetric structure of the typhoon depended on the phase of the simulated typhoon. The maximum range of the simulated central pressure was $\sim 10 \mathrm{hPa}$ during the mature phase of the simulated typhoon. The effect of preexisting oceanic conditions on the axisymmetric structure of the simulated typhoon was seen in the generation of a supergradient flow and the associated upward motion during the intensification phase, in downward air motion accompanied by evaporative cooling and outflow above the inflow boundary layer during the mature phase, and in a radially inward jet during the decaying phase. These effects are independent of whether the atmosphere model is coupled with an ocean model.

(2) We found a high correlation between the simulated central pressure and the axisymmetric mean horizontal specific humidity flux, which indicates that the horizontal specific humidity flux has potential as a new metric for the intensity prediction of a tropical cyclone (TC). By contrast, the relationship between the simulated maximum wind speed and the axisymmetric mean horizontal specific humidity flux depended on the phase of the simulated typhoon, because preexisting oceanic conditions affect the axisymmetric structure of the simulated typhoon differently during different TC phases. The simulated wind-pressure relationship obtained with the coupled model agrees well with the relationship proposed by Koba et al. [31] and with the best track data only during the decaying phase.

(3) The impacts of preexisting oceanic conditions on simulated horizontal fields of the atmosphere and ocean differed between the typhoon and a nearby stationary front. Around the stationary front, the impact of preexisting oceanic conditions on hourly precipitation was closely related to the impact on surface wind speeds, whereas the impact on surface air temperature was greatly affected by that on sea surface temperature through the latent heat flux.

(4) Validation results against KEO observations showed that changes in preexisting oceanic conditions did not improve the simulation of sea-level pressure, air temperature, or sea surface temperature at the KEO buoy site, perhaps because the impact of preexisting oceanic conditions on TC track simulations is small.

\section{Acknowledgments}

The authors are grateful to two anonymous reviewers for helpful comments that improved the paper. A. Wada is grateful to Dr. M. F. Cronin for providing the KEO observations reported in Section 3.4. This work was supported by the Japan Society for the Promotion of Science (JSPS), KAKENHI Grant nos. 22540454 and 25106708, and by the Japanese Ministry of Education, Culture, Sports, Science and Technology (MEXT), KAKENHI Grant no. 23106505. Generic Mapping Tools (http:/gmt.soest.hawaii.edu/) software was used to draw the figures.

\section{References}

[1] E. H. Palmén, "On the formation and structure of tropical cyclones," Geophysica, vol. 3, pp. 26-38, 1948.

[2] K. A. Emanuel, "An air-sea interaction theory for tropical cyclones. Part I: steady-state maintenance," Journal of the Atmospheric Sciences, vol. 43, no. 6, pp. 585-604, 1986.

[3] K. A. Emanuel, "Sensitivity of tropical cyclones to surface exchange coefficients and revised steady-state model incorporating eye dynamics," Journal of the Atmospheric Sciences, vol. 52, no. 22, pp. 3969-3976, 1995.

[4] G. J. Holland, "The maximum potential intensity of tropical cyclones," Journal of the Atmospheric Sciences, vol. 54, no. 21, pp. 2519-2541, 1997.

[5] J. F. Price, "Upper ocean response to a hurricane," Journal of Physical Oceanography, vol. 11, no. 2, pp. 153-175, 1981.

[6] A. Wada, "Numerical simulations of sea surface cooling by a mixed layer model during the passage of typhoon rex," Journal of Oceanography, vol. 61, no. 1, pp. 41-57, 2005. 
[7] A. Wada, H. Niino, and H. Nakano, "Roles of vertical turbulent mixing in the ocean response to Typhoon Rex (1998)," Journal of Oceanography, vol. 65, no. 3, pp. 373-396, 2009.

[8] I. Ginis, "Ocean response to tropical cyclone," in Global Perspective on Tropical Cyclones, R. L. Elsberry, Ed., WMO/TD-No. 693, pp. 198-260, Geneva, Switzerland, 1995.

[9] F. Sakaida, H. Kawamura, and Y. Toba, "Sea surface cooling caused by typhoons in the Tohoku Area in August 1989," Journal of Geophysical Research C, vol. 103, no. 1, pp. 1053-1065, 1998.

[10] I.-I. Lin, C.-C. Wu, K. A. Emanuel, I.-H. Lee, C.-R. Wu, and I.F. Pun, "The interaction of supertyphoon Maemi (2003) with a warm ocean eddy," Monthly Weather Review, vol. 133, no. 9, pp. 2635-2649, 2005.

[11] B. Qiu and K. A. Kelly, "Upper-ocean heat balance in the Kuroshio extension region," Journal of Physical Oceanography, vol. 23, no. 9, pp. 2027-2041, 1993.

[12] B. Qiu, "The Kuroshio Extension system: its large-scale variability and role in the midlatitude ocean-atmosphere interaction," Journal of Oceanography, vol. 58, no. 1, pp. 57-75, 2002.

[13] S. Chen, "The Kuroshio extension front from satellite sea surface temperature measurements," Journal of Oceanography, vol. 64, no. 6, pp. 891-897, 2008.

[14] M. Nonaka and S.-P. Xie, "Covariations of sea surface temperature and wind over the Kuroshio and its extension: evidence for ocean-to-atmosphere feedback," Journal of Climate, vol. 16, no. 9, pp. 1404-1413, 2003.

[15] K.-S. Yun, J. C. L. Chan, and K.-J. Ha, "Effects of SST magnitude and gradient on typhoon tracks around East Asia: a case study for Typhoon Maemi (2003)," Atmospheric Research, vol. 109-110, pp. 36-51, 2012.

[16] N. A. Bond, M. F. Cronin, and M. Garvert, "Atmospheric sensitivity to SST near the Kuroshio Extension during the extratropical transition of Typhoon Tokage," Monthly Weather Review, vol. 138, no. 7, pp. 2644-2663, 2010.

[17] M. Kunii and T. Miyoshi, "Including uncertainties of sea surface temperature in an ensemble Kalman Filter: a case study of Typhoon Sinlaku (2008)," Weather and Forecasting, vol. 27, pp. 1586-1597, 2012.

[18] A. Wada and N. Usui, "Impacts of oceanic preexisting conditions on predictions of Typhoon Hai-Tang in 2005," Advances in Meteorology, vol. 2010, Article ID 756071, 15 pages, 2010.

[19] A. Wada, N. Kohno, and Y. Kawai, "Impact of wave-ocean interaction on typhoon hai-tang in 2005," Scientific Online Letters on the Atmosphere, vol. 6, pp. 13-16, 2010.

[20] N. Usui, S. Ishizaki, Y. Fujii, H. Tsujino, T. Yasuda, and M. Kamachi, "Meteorological Research Institute multivariate ocean variational estimation (MOVE) system: some early results," Advances in Space Research, vol. 37, no. 4, pp. 806-822, 2006.

[21] M. A. Bender, I. Ginis, and Y. Kurihara, "Numerical simulations of tropical cyclone-ocean interaction with a high-resolution coupled model," Journal of Geophysical Research, vol. 98, no. 12, pp. 23-263, 1993.

[22] J. C. Ohlmann and D. A. Siegel, "Ocean radiant heating. Part II: parameterizing solar radiation transmission through the upper ocean," Journal of Physical Oceanography, vol. 30, no. 8, pp. 1849-1865, 2000.

[23] A. Schiller and J. S. Godfrey, "A diagnostic model of the diurnal cycle of sea surface temperature for use in coupled ocean-atmosphere models," Journal of Geophysical Research C, vol. 110, no. 11, Article ID 11014, pp. 1-9, 2005.
[24] Y.-L. Lin, R. D. Farley, and H. D. Orville, "Bulk parameterization of the snow field in a cloud model," Journal of Climate \& Applied Meteorology, vol. 22, no. 6, pp. 1065-1092, 1983.

[25] J. Kondo, "Air-sea bulk transfer coefficients in diabatic conditions," Boundary-Layer Meteorology, vol. 9, no. 1, pp. 91-112, 1975.

[26] J. B. Klemp and R. Wilhelmson, "The simulation of threedimensional convective storm dynamics," Journal of the Atmospheric Sciences, vol. 35, pp. 1070-1096, 1978.

[27] J. W. Deardorff, "Stratocumulus-capped mixed layers derived from a three-dimensional model," Boundary-Layer Meteorology, vol. 18, no. 4, pp. 495-527, 1980.

[28] M. Sugi, K. Kuma, and K. Tada, "Description and performance of the JMA operational global spectral model (JMA-GSM88)," Geophysical Magazine, vol. 43, pp. 105-130, 1990.

[29] K. Ueno and N. Kohno, "The development of the third generation wave model MRI-III for operational use," in Proceedings of the 8th International Workshop on Wave Hindcasting and Forecasting, pp. 1-7, Oahu, Hawaii, USA, November 2004.

[30] P. K. Taylor and M. J. Yelland, "The dependence of sea surface roughness on the height and steepness of the waves," Journal of Physical Oceanography, vol. 31, no. 2, pp. 572-590, 2001.

[31] H. Koba, T. Hagiwara, S. Asano, and S. Akashi, "Relationships between CI number from Dvorak's technique and minimum sea level pressure or maximum wind speed of tropical cyclone," Journal of Meteorological Research, vol. 42, pp. 59-67, 1990 (Japanese).

[32] R. A. Houze Jr., S. S. Chen, B. F. Smull, W.-C. Lee, and M. M. Bell, "Hurricane intensity and eyewall replacement," Science, vol. 315, no. 5816, pp. 1235-1239, 2007.

[33] R. A. Houze Jr., "Clouds in tropical cyclones," Monthly Weather Review, vol. 138, no. 2, pp. 293-344, 2010.

[34] R. K. Smith, M. T. Montgomery, and S. Vogl, "A critique of Emanuel's hurricane model and potential intensity theory," Quarterly Journal of the Royal Meteorological Society, vol. 134, no. 632, pp. 551-561, 2008.

[35] R. K. Smith, M. T. Montgomery, and N. van Sang, "Tropical cyclone spin-up revisited," Quarterly Journal of the Royal Meteorological Society, vol. 135, no. 642, pp. 1321-1335, 2009.

[36] A. Wada and N. Usui, "Importance of tropical cyclone heat potential for tropical cyclone intensity and intensification in the Western North Pacific," Journal of Oceanography, vol. 63, no. 3, pp. 427-447, 2007.

[37] A. Wada, "Idealized numerical experiments associated with the intensity and rapid intensification of stationary tropicalcyclone-like vortex and its relation to initial sea-surface temperature and vortex-induced sea-surface cooling," Journal of Geophysical Research D, vol. 114, no. 18, Article ID 18111, 2009.

[38] A. Wada, N. Usui, and K. Sato, "Relationship of maximum tropical cyclone intensity to sea surface temperature and tropical cyclone heat potential in the North Pacific Ocean," Journal of Geophysical Research D, vol. 117, Article ID 11118, 2012.

[39] A. Wada, "Numerical study on the effect of the ocean on tropical-cyclone intensity and structural change," in Atmospheric Model Applications, I. Yucel, Ed., pp. 43-68, InTech, Rijeka, Croatia, 2012.

[40] R. J. Small, S. P. deSzoeke, S. P. Xie et al., "Air-sea interaction over ocean fronts and eddies," Dynamics of Atmospheres and Oceans, vol. 45, no. 3-4, pp. 274-319, 2008.

[41] M. F. Cronin, C. Meinig, C. L. Sabine, H. Ichikawa, and H. Tomita, "Surface mooring network in the Kuroshio extension," IEEE Systems Journal, vol. 2, no. 3, pp. 424-430, 2008. 
[42] Y. Miyamoto and T. Takemi, "A transition mechanism for the spontaneous axisymmetric intensification of tropical cyclones," Journal of the Atmospheric Sciences, vol. 70, pp. 112-129, 2013.

[43] Y. Wang and J. Xu, "Energy production, frictional dissipation, and maximum intensity of a numerically simulated tropical cyclone," Journal of the Atmospheric Sciences, vol. 67, no. 1, pp. 97-116, 2010.

[44] S. Kanada, A. Wada, M. Nakano, and T. Kato, "Effect of planetary boundary layer schemes on the development of intense tropical cyclones using a cloud-resolving model," Journal of Geophysical Research D, vol. 117, no. 3, Article ID 03107, 2012.

[45] Y. Wang and C.-C. Wu, "Current understanding of tropical cyclone structure and intensity changes-a review," Meteorology and Atmospheric Physics, vol. 87, no. 4, pp. 257-278, 2004.

[46] R. L. Elsberry and P. A. Harr, "Tropical Cyclone Structure (TCS08) field experiment science basis, observational platforms, and strategy," Asia-Pacific Journal of Atmospheric Sciences, vol. 44, no. 3, pp. 209-231, 2008.

[47] C.-C. Wu, Y.-H. Huang, and G.-Y. Lien, "Concentric eyewall formation in typhoon sinlaku (2008). part I: assimilation of T-PARC data based on the ensemble kalman filter (enkf)," Monthly Weather Review, vol. 140, no. 2, pp. 506-527, 2012.

[48] E. D’Asaro, P. Black, L. Centurioni et al., “Typhoon-ocean interaction in the western North Pacific. Part 1," Oceanography, vol. 24, no. 4, pp. 24-31, 2011. 

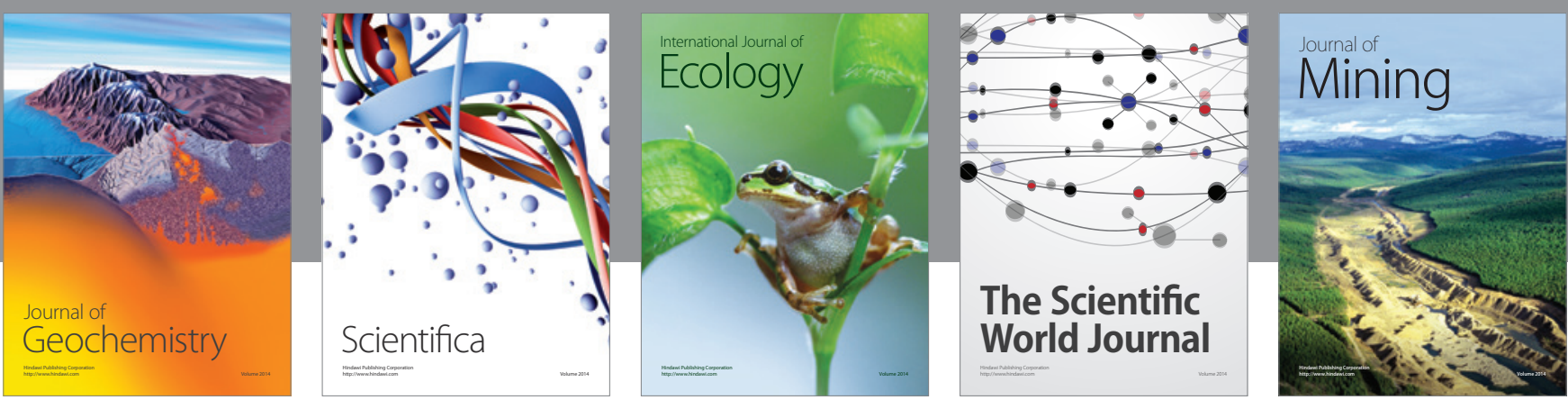

The Scientific World Journal
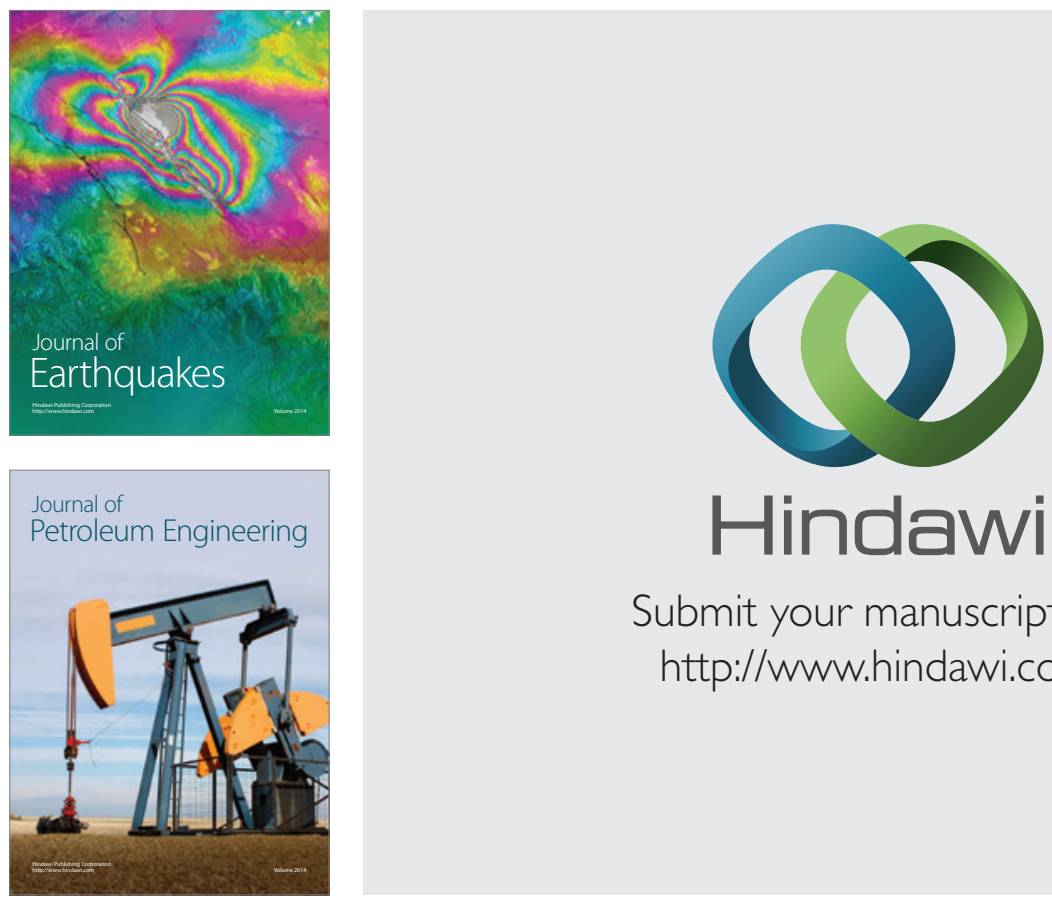

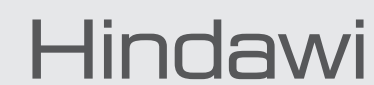

Submit your manuscripts at

http://www.hindawi.com
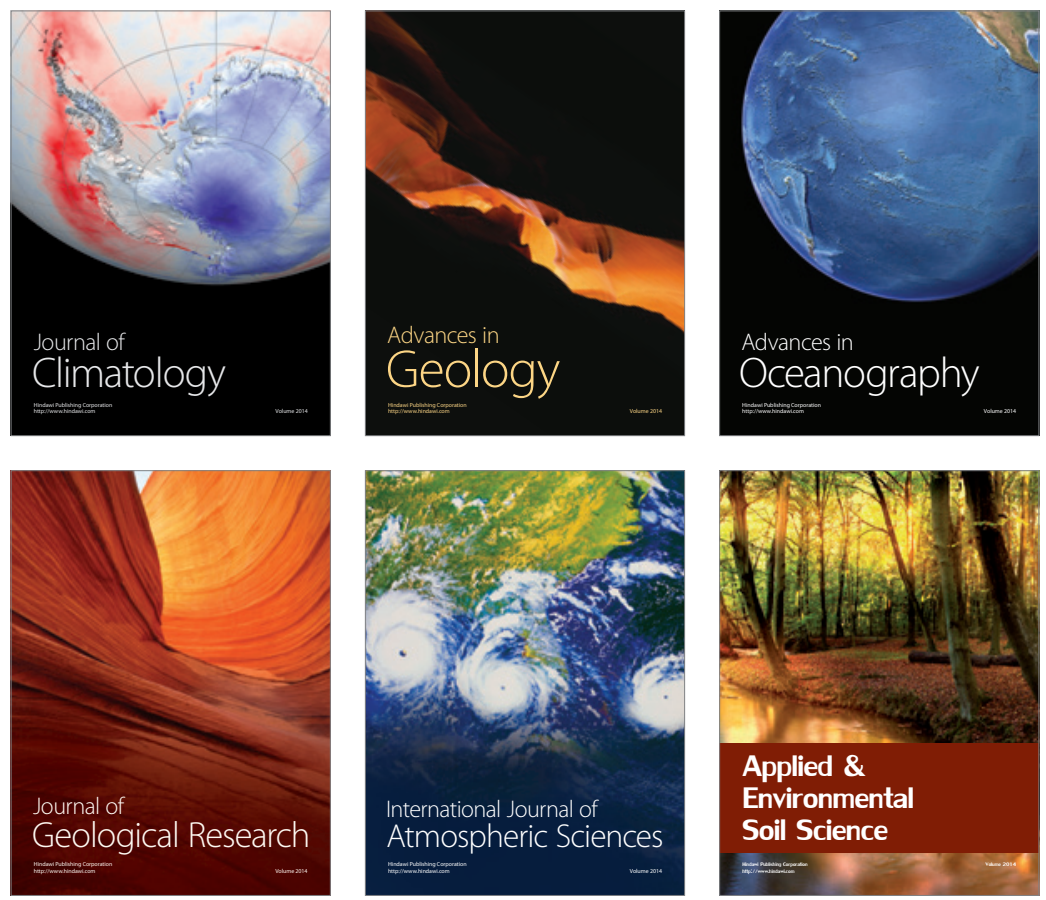
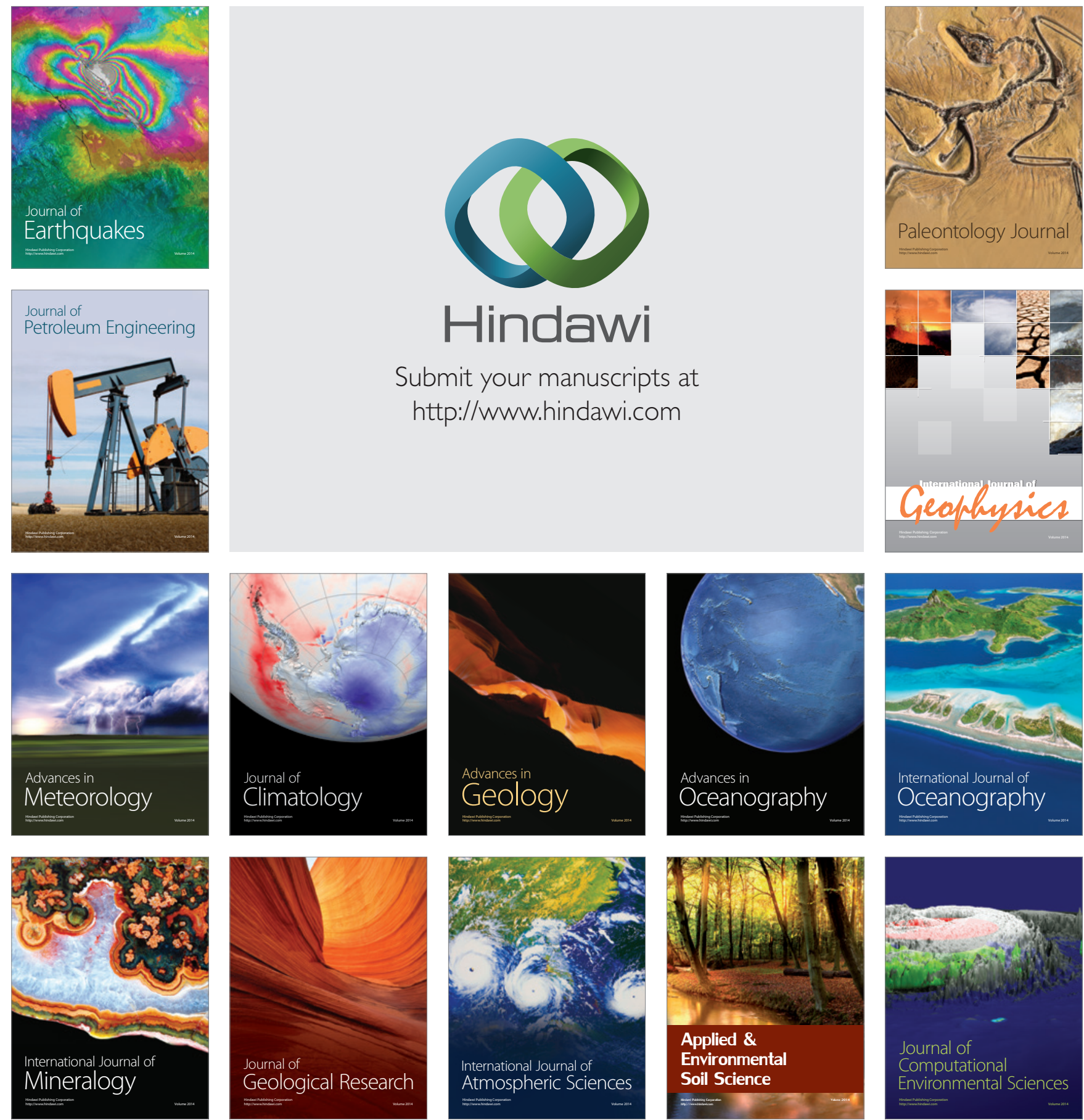